Portland State University

PDXScholar

$4-1-1970$

\title{
Versuch einer ästhetischen Wertsetzung: zur Kunsttheorie von Benn und Nietzsche
}

Kathryn M. Horváth

Portland State University

Follow this and additional works at: https://pdxscholar.library.pdx.edu/open_access_etds Let us know how access to this document benefits you.

\section{Recommended Citation}

Horváth, Kathryn M., "Versuch einer ästhetischen Wertsetzung: zur Kunsttheorie von Benn und Nietzsche" (1970). Dissertations and Theses. Paper 923.

https://doi.org/10.15760/etd.923

This Thesis is brought to you for free and open access. It has been accepted for inclusion in Dissertations and Theses by an authorized administrator of PDXScholar. Please contact us if we can make this document more accessible: pdxscholar@pdx.edu. 
VERSUCH EINER ÄSTHETISCHEN WHETSEYZWNG:

ZUR KNISTTHEORTH NON

BEMN UND NIETZSCTE

by

Kathryn M: Horváth

A thesis submitted in partial fuitillment of the requirements for the degree of

MASTER OF ARTS

in

GERMAN

Fortland State University

I970.

\section{PORTLAND STATE UNIEERSTTY LIBRARY}


AR ABSTRACT OF THE THESIS OF Eathryn M. Forvath for the Master of Arts In Germen presented April $15,1970$.

Title: Versuch einer ästhetischen Wertsetzang: anx Enathoorie vox Bem und Nietzsche. (Attempt at an Esthetic Valuation: on the frt meory of Benn and Nietzschel.

APPEOVED BY MFMBERS OT THE TESSTS COMMTIMEEE:
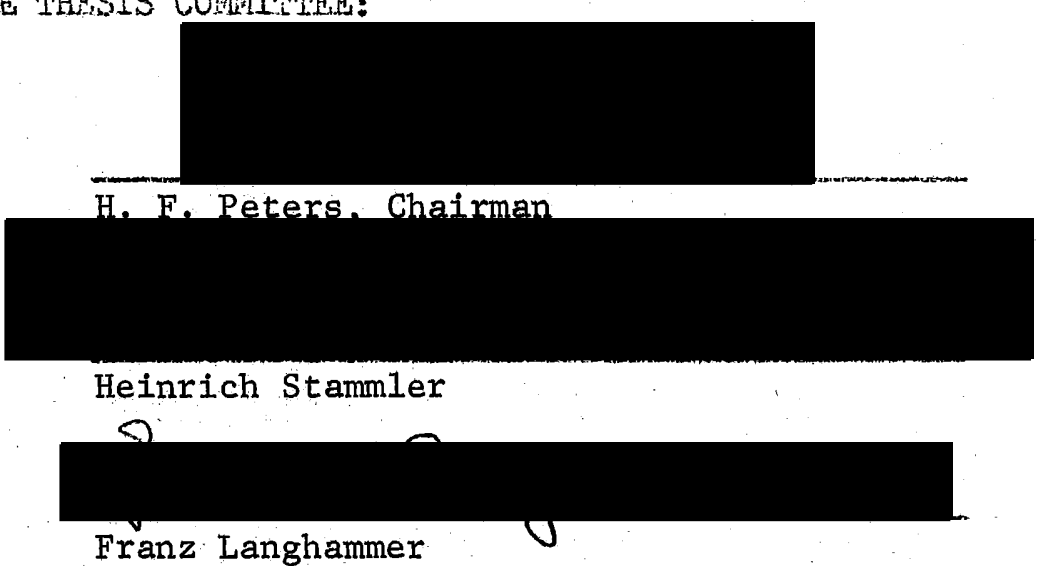

The German expressionist poet Gotifried Bern (1886-1956), a grest tamirer of the philosopher, psychologist, post, anti-Christ and art theoreti. cian Rriedrich Hietzsche (1844-1900), ruoted and commented on the works of the latter from 1926 until his death. Ben' seferences to lietasche reno from the mere mention of the neme in some works to entire poens (c.t. "sils

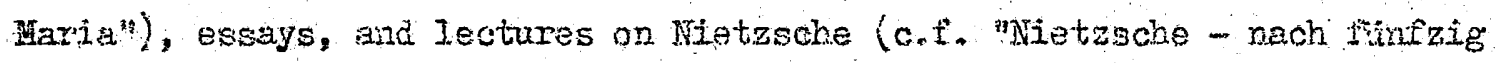
Jahren"). Bern nade no secret of his bero-torship for Hetzsche and considerod himself the latter's heir es fer as his theory of art tas conoerned. Three key jdeas on art, which Bern took owor from Nietrsche and quoted, elacorated, and comented upon are: the ilae that the world and existence are justifiable 
only as esthetic phenomena, the idea of art as the "Olymp des Scheinis", and the idea of art as the actual task of man, as his metaphysical activity. In my thesis I' have attempted to show that in spite of Benn's great admiration of Nietzsche as an art theoretician, in spite of the fact that Benn used Nietzsche's art vocabulary and took over quotations from his works alinost verbatim, in spite of the fact that both Benn and Nietzsche saw in art the salvation for inan in the midst of the european nihilism, Benn misinderstood Nietzsche's basic message.

I have explained that Benn and Nietzsche looked upon nihilism from two divergent points of view. Nietzsche concerned himself with giving the old "absolute" values, which were in their death-throes, the coup de grace and tried to establish in his "Übermensch" idesl, an ideal which man is not meant to ever attain, but must continuously strive for, a new set of velues, a new "metaphysias", one not of the supematural world, but of the natural world, different from the metaphysics of the Christian-Platonic tradition in that it looked upon man as a unity, a polarity of the material and the non-naterLal and sought to bring them in harmony not through the violence of the extermination of the passions acd the drives, but rather tarough their sublimation. For Nietzsche, nikilism was a brief temporary stage in the history of ideas, the natural and necessary conclusion of the old absolute values, an end the seed of which the old values had borne in themselves from their very inception, since they were based upon a denial of and violence against nature. Nietzsches attitude was a dynamic, revolutionary and creative one, and he saw art at the center of his new valuation, es an enticeruent to life, as that which leads man to an affirmation of the totelity of life - its pain and sorrow as well as its 
joys.

For Bern, on the other hand, who saw in Nietzsche not a positor of new values, but a destroyer of the old ones, a materialist and a disciple of Darwin, nihilism was insumountable and here to stay. His attitude was a hercic nihilism - one of resignation, a static, quietistic attitude. As a result of man's progressive cerebration and his subsequent loss of a genuine relationship to nature, the material and the non-material aspects of man, life and Intellect were considered by Benn to constitute an irreconcilable antinomy. FAs a result he also considered art and life as two separate spheres and saw art as an escape, as the artist's seareh for his identity. From this point of view Benn developed his theory of absolute art, of art for the sake of art, of art as form.

I have atterpted to show that Benns misunderstanding of Nietzsche on the subject of art - notwithstanding the similarity of the vocabulary employed by the two authors - stems from his misunderstanding of Nietasche as a philosopher, from the fact that Benn overlooked certain aspects of the writings of Nietzsche in favor of othex aspects. By Benn's own admission, his favorite book on Nietzsche was Ermst Bertrem s nietzsche: Attempt at a Mythology" ... (1918). I have examined this book, under whose spell Benn had fallet, and have found that Betram, a member of the George-Kreis, the members of which used the Nietrsche of the Nietzsche "Legend" to their own ends, made no claim to either histarical or philosophieal accuracy, indeen that he overloaked Nietasche's philosophy completely, that his goal was to perpetuate the Nietasche "cult" of the Kreis. For Betram Nietzsche was not a philosopher, but a mystic and a saint.

It is well-known that Nietzsche's vocebulary lends' itself especially well 
to misinterpretations of all sorts, intentional as well as unintentional. One need" only think of what the Nazis were able to do with the "blond beast" and the "superman", words taken out of context and used as slogans to fit a given ideology. The first scientific work which dealt sexiously with Nietzsche as a philosopher was that by Jaspers in 1936, in which a brief half-page is-devoted to art. The other scientific works on Nietzsche as a philosopher have appeared only much more recently. 
TO THE OFPICE OF GRADUATE STUDIES:

The members of the Committee approve the thesis of Kathryn Mi Horváth presented April 15, 1970.

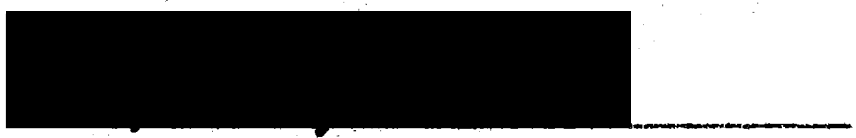

H. F. Peters, Chairman

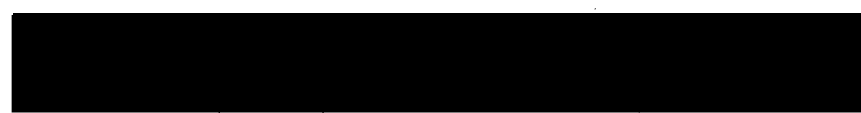

Heinrich Stammler

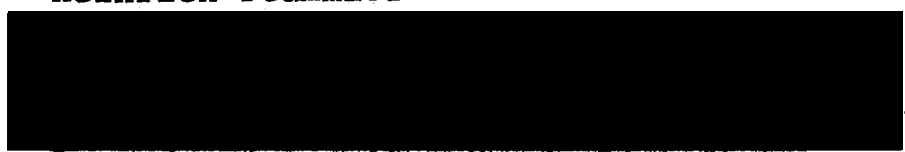

Franz Langhammer

AFPROVED:

H. F. Peters, Chairman, Department of Foreign Languages

Frank foberts, Acting Dean of Graduate Studies

April 15, 1970 
INHAITSVERZEICHNIS

BINLEITUNG $\ldots \ldots \ldots \ldots$

ERSTER TEIL:DIE GRUNDLAGENKRISE

BENNS SEHNSUCE'T NACH DRR VERLORENEN MITTE

Progressive Zerebration und Verlust des prälogischen

Zustiandes...................

Wirklickikeitserzeugung und -zusamnenbmach ........

Metaphysischer Verrat ..............

Verlust der kontinuierlichen Psychologie .......

Die Antinomie von Geist and Leben .........

Das Bionegative............................... 20

NIEIZSCHE UND DER EUROPÄISCHE NIHILISRUS . . . . . . . 23

Décadence und Entwertung der bisherigen höchsten Werte.

Die axiologische Auseinandersetzung: Diesseits und Jenseits Polemik gegen die Metaphysik ..........

ZWEITER TEIL: VIRSTCH EINER NEUEN WERTSETZUNG

MIETZSCEES METAPEYSTK DES WILIERSS ZOR MACHT . . . . .

KUNST UND DAS ERHÖHTE LEBEN BEI NIETZSCHE _.......

KUNSP UND WAHRHEIT BEI NIETZSCHE

48

BENN UND DIE MIONOEOGISCH-MONONANE KUNIST 
RESIGNATION UND AMOR FATI ...............

I'ART POUR I'ART . . . . . . . . . . . . .

68

BENNS VERTRAUTHEIT MIT NIETZSCHE . . . . ......

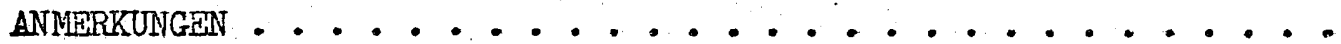




\section{EINLEITUNG}

Wer die schriften Gottfried Benns auch nur flüchtig durchliest, dem wird auffallen, wie oft der Name Nietzsches im Werke Benns fällt. Mindestens hundertmal wird der Name erwähnt, und in den Zitaten, die in vielen Fällen folgen, bezieht sich Benn auf die Hauptwerke Nietzsches von dessen Erstlings1. Leistung, "Die Geburt der Tragọdie", bis "Ecce Homo". Vom Jahre 1925, in dem Benns erste Bemihungen um Nìetzsche im Rundfunkdialog "Können Dichter die

* WeIt ändem?" NJederschlag fanden, bis zu des Dichters Lebensende, bis also 1956, beschäftigte sich Benn mit den Philosophen. An mehreren Stellen der Wexke Benns kommt seine abgöttische, fast grenzenlose Verehmung für Nietzsche klar zum Ausdruck. In einem Brief aus dern Jahre 1949 schrieb der 63-jährige Benn: "Meine Götter geblieben sind immer noch Hejnrich Mann, Nietzsche und Taine, an denen habe ich mich gebildet." ${ }^{1}$ An einer anderen Stelle nannte er Nietzsche "nach Goethe das grösste weisse Genie", ${ }^{2}$ und schloss den Bundfunivortrag "Nietzsche - nach fünfzig Jahren" nit der Apotheose: "Und dann sagte er: 'Traum ist die Welt und Rauch vor den Augen eines ewig Unzufriedenen' nun wurde er, der es sagte, für uns selbst zum Traum, und wir gehen keinen Schritt unseres Weges mehr ohne die Anbetung dieses Traums." 3

Dass sich Benn fast lebenslänglich mit Nietzsche beschäftigte, dass er Ihn vergötterte, lässt sich kaun bestreiten. Fine konsequente Benn-Lektiire erweist auch, dass Ben in Wietzsche in erstex Linie den Dichter, das Sprachgenie und den Kinst]ex und Kunstheoretiker erkante, und dass er sich in Fragen der Kunst als dessen Erbe betrachtele. Drei Gedanken, die Benn aus 
der Ästhetik Nietzsches übernahm und auf die er sich andauernd berief sind: die Kunst als "Olymp des Scheins", 4 die Rechtfertigung der Welt und des Daseins als ästhetisches Phänomen ${ }^{5}$ und die Kunst als metaphysische Tatigkeit, letzteres ein Gedanke, den Benn neunmal zitiert und variiert. 6

Die Frage wäre nun, ob Benns Auslegung dieser Gedanken, die er oft rhapsodisch aufgreift, sich damit deckt, was Nietzsche zu verkinden beabsichtigte. Es ist die Aufgabe dieser Arbeit, Benns. Missverständnis des eigent+ Iichen Sinnes der Nietzscheschen $̈$ sthetik zu erörtern, ein Missverständnis, das darauf beruht, dass Benn die Philosophie Nietzsches ïbersah und seine * Iehren im bjologisch-darwinistischen Sjnne, dazu noch nihilistisch, missdeutete. Obgleich der Weg aus dem allgemeinen Zerfall der bisherigen höchsten Wertie sowohl den Philosophen des ausgehenden 19. Jahrhunderts als auch den Dichter des 20. Jahrhunderts zur Kunst - zu einer ästhetischen Wertsetzung führt, sind es im Grunde zwei verschiedene Wege, und mag das Vokabular der beiden in puncto Kunst auf den exsten Blick noch so ähnlich erscheinen, so bringt eine nähere Untersuchung zwei völlig verschiedene Auffassungen zutage. Der erste Teil dieser Arbeit soll zur Darstellung der Grundlagenkrise, in dersich Benn und Nietzsche befanden und zur Untersuchung jhrer Einstellung zu dieser Krise dienen. Im zweiten Teil erfolgt eine Abhandlung über den Versuch beider Autoren, den allgemeinen Wertverlust durch die Kunst zu ersetzen und eine Enorterang der Unterschiede zwischen den Kunstheorien der beiden. Zum Schluss wird dann das Fazit gezogen, mit einer Darlegung der Grinde, auf denen das Misswerständnis beruht. 
ERSTER TEII

IIE GRUNDLAGGEUKRISE 
In den Werken Benns, sowohl in den Prosastücken als auch in den Gedichten, kommen häufig Ausrufe eines verzweifelten Ich zum Ausdruck, eines an der Gespaltenheit der Persönlichkeit leidenden Ich, das sich nach Finheit sehnt. Einst, in der graven Vorzeit, gab es diese Finheit, als der Mensch seine jetzige Geistesart noch nicht innehatte, und manche der Naturvölker haben diese Einheit nicht verloren. Diesen Zustand, in dem Köper und Geist, Leben und Denken nicht gespalten sind, nennt Benn den prälogischen Zustand (vgl. "Provoziertes Leben", III, S. 898: "... der Grosse Soekelgesang prälogischer, aber noch erfüllungsfähiger Welten"), und nach diesem Zustand. vor der "Trennung von Ich und Welt" sehnt sich das hochentwickelte Wesen, der moderne, zivilisierte Mensch zurick. I

Den Begriff "prälogische Geistesart" verdankt Benn dem fxanzösischen Anthropologen Lucien Lévy-Bruhl, der in einer Reihe von Bichern die Denkweise der heutigen Naturvölker beschreibt. In seinem Werk "Die geistige Welt der Primitiven" berichtet Iévy-Brubl über die "mehr mystische als logische Geistesart der prinitiven Gesellschaft", ${ }^{2}$ und forscht nach den Grunden für die Abneigung der Naturvölker gegen das, was die Iogiker kausalanalytische und diskursive Denkoperationen nerinen, eine Abneigung, die keineswegs auf Unfähigkeit beruht, sondem auf den geistigen Gewohnhejten dieser Völker und mjt ihrer Lebensweise eng verbunden ist. Die Naturvôlker sind notgedrungen mit 
der Sorge für ihren Iebensunterhalt dermassen beschäftigt, dass ihre Gedanken nicht über ihre Gesundheit und ihren Erfolg im Fischen, Handeln und Jagen hinausgehen. Daraus zi.hen sie ihre Folgerungen für ihren Aberglauben. Die Welt ist für sie eine Einheit, allerdings eine geheimnisvolle, und natürliche Erscheinungen werden auf übernatürliche Ursachen zurückgefuhrt. Nichts wird als zufällig betrachtet. Natürliche Ursachen werden als Werkzeuge den unsichtbaren Màchtén zugeschrieben, die dem Menschen bald feindlich, bald freundlich gesinnt sind, die sich aber dunch Opfer aller Art beschwichtigen lassen. So lässt es sich leben, denn wenn einem etwas missgluickt, so bedeutet es, dass man ein 1) Tabu verletzt hat, und man versucht es wieder gutzumachen. Man ist sozusagen mitverantwortlich für das, was geschieht. Wird man von allen "guten" Geisterm verlassen, so ist man mindestens teilweise selbst schuld. ${ }^{3}$ Diese weltbetrachtung gibt dem Naturmenschen einen Halt und bietet eine Erklärung und einen Grund für vieles, was der zivilisierte Mensch Zufall nennt. Es ist eine synthetische Weltbetrechtung, und der Mensch fühlt sich in solch einex. Welt nicht isoliert.

Fir Benn bedeutet der Schritt weg von dieser mystischen, präanalytischen Weltbetrachtung, die Entwicklung des Lebenden zu dem diskursiv Denkenden, zum Bewussten, nicht nur Fortschritt, sondern auch Katastrophe. Es Ist ein Beispiel des Iebensgesetzes "tragischer Dialektik", dass "alle Dinge ihren wł derspruch in sich tragen". 4 Das Bewusstwerden hat der Mensch teuer bussen museen, denn Bewusstsein bedeutet Leiden. Dieses Ieiden am Dasein und am Bewrisstoesn ist es, das dem jungen Benn den verzweifelten Ausruf entlockt: "0 dess wir unsere Ururahnen wären./ Ein Klümpchen Schleim in einem warmen Moor./ ... Schon ein Iibellenkopf, ein Möwenflügel / wäre zu weit und ljtte schon zu sehr." 5 Der 
Mensch leidet an Fntwurzelung. Im Urzustand gab es noch keine Spannung. zwischen Innen und Aussen, zwischen Ich und Welt, keinen Zwiespalt zwischen Individuum und Natur, der bei Benn das primäre existentielle Problen, die fundamentale Antithese darstellt."

Mit den Verlust des prälogischen Zustandes, den die menschliche somatische Entwicklung notwendigerweise mit sich brachte, begann ein unaufhaltsamer Prozess, von Benn "progressive Zerebration" genannt. ${ }^{6}$ Dieser Begriff K au der Anthropologie und Hirnforschung, von dem Wiener von Economo aufge* stellt, bezeichnet einen deut.lich erkennbaren Zuwachs an Intellektualisierung, die die Menschheit in Verlauf ihrer Geschichte aufweist. ${ }^{7}$ Wie Benn in dem 3 Aufsatz "Der Aufbau der Persönlichkeit" behauptet, 8 hat diese Intellektualisierurg eine biologischi-organische Grundlage, ist also somatisch bedingt, und list physiologisch an dem progressiven Zuwachs an Schädelumfang erkennbar. 9 Mit der progressiven Zerebration begann das Ich zu denken: die Umwelt zu analysieren, pxüfen, zerstücken und zerdenken. Das Ich entfernte sich von der Natur sinnlich, trat ifre aber geistig näher. In seinem Versuch, die welt be-grifflich zu ibersteigen, entfremdete sich das Ich von ihr und isolicrte sich. Diese Isolierung nent Benn die "Trigidisiemung des Ich". ${ }^{10}$ Das frigidisierte Ich ist "der tragische Narziss, der inhaltlose, ziellose und sinnlose schnittpunkt, das absolute Ich, das von Schweigen umgeben ist", 11 denn sovald die Welt fuir den Menschen begrifflich übersteigbar wurde, verlor er das Einssein mit ihr, stellte er sich ihr gegenüber.

Benns Ansicht nach ist der Prozess der progressiven Zerebration mit dem Phänomen des Nihilismus chronologisch und inhaltlich verbunden. Sobald der Mensch mit Hilfe der moderren Wissenschaft instande war, den Kosmos zu be- 
greifen, verlor dieser das Geheimnisvolle und Mysteriöse, das Tragische entwertete sich und nur das Banale blieb. So entstand die Nivellierung der Werte, der Nihilismus: rein radikaler Positivismus in Bezug auf Naturwissenschaft und Soziologie. Mit dem Darwinismus wurde der Mensch gut und alle Menschen gleich, alle ihre Leiden "medizinisch oder sozial bekämpfbar". 12 Als "die Welt zerdacht" wurde, 13 verlor selbst dieses Denken seinen Sinn im Banalen und wurde fregwüdig. In dem Stück "Drej alte Männer" heisst es:"

Onser Grosshirn ist der letzte Sprung, nun lëuft er aus ... Das wesentliche Denken ist so entartet, dass es nur noch in Zusammenhängen denkt mit Sicherungen nach rechts undilinks, ein Denken okne Wagnis, mechanische Absonderung grauer menliger kausal. ver-mörtelter Mitropawindungen in einem Rundschädel, der nur noch an industrielles Fortkommen denkt - aber auch dainit wird es diixf.ti.g. 14

- Die Welt wurde zerdacht, Spannung und Zwiespalt entstariden zwischen Ich und Welt und das Ich wurde von seinem Naturzustand entwurzelt. Niemand würde leugnen, dass sich das Ich "nicht sehr verlässlich zu Hause" füht in der"gedeuteten WeIt". Der Naturzustand ist für den Menschen verloren: daran ist nichts zu ändern. Aber das menschliche Gehirm, das menschliche Bewusstsein, ist in Schichten entstanden, und im Gehirn liegt "die Vorwelt gesammelt mit ihren verdeckten Kräften." ${ }^{15}$ Benn spricht in seiner "Akademie-Rede" von diesem Schichtungscharakter der anthropologischen Substanz und meint, wir . . txügen die frühen Völker in unserer Seele, und, obwohi die primitive Form des Ich fiur den modemen Menschen als Dakerzustand verloren sei, komme sie jedoch in gewissen Zus.tänden - Traum, Rausch, Trancezuständen und in gewissen Geisteskrankheiten - gelegentlich und bruchstückweise zum Vorschein. Fir den Kuinstler, der besonders sensibel ist und wohl am meisten an den Folgen der progressiven Zerebration leidet, gilt es, den pxälogischen Zustand zu provozieren, 
der, wie wir sehen werden, auch den schöpferischen Prozess einleitet. ${ }^{16}$ Die erwähnten Zustände nennt Benn die "hyperämischen Reiche". ${ }^{17}$ Hyperämie, ejn Begriff aus der medizinischen Fachsprache, bezeichnet eine gesteigerte Blutfülle in einem begrenzten körperlichen Bereich. ${ }^{18}$ Synonyme sind die Aus"drücke "Kongestion", "Wallungen" und "Blutwallungen". Diese Zustände wexden won gesteigerten Bewusstseinszuständen begleitet und könrien unter enderem * auch mittels Alkohol und Rauschgift - dureh das, was die Ratio lockert - eingeleitet werden (vgl. die Gediehte "Kokain" und "0 Nacht-:" I, S. 52,53). Das Asolierte Ich, das exdhaft geburdene und kegrenzte Ich wird dam zu einem Anersprengten Ich" ("Kokain"), das sich uber den zerebralisierten Zustand hinaushebt, ihn transzendiert, in efnen Zustand "mystischer Partizipation" gerät and darn mit dem "Urgesicht" eins wird. Der Begriff "ruystische Partizipation", aen C.G. Jung als ein Überbleibsel des Urzustandes des Einsseins vor subjekt urid Objekt bezeichnet und der darin besteht, dass sich das Subjekt vorn Objekt nicht klar unterscheiden kann, 19 wixd von Benn auch "Vermischung" genannt. Den Prozess der Vermischung, das Einssein nit dem Ureinen - von Benp Urgesicht genannt -, das Transzendieren des Ich ins Allgemeine, nennt Benn seine "hyperämische Metephysik", 20 und sie wird von ihm, dem die Erkenntnis zum Verhängnis wurde, zuerst im Sinne eines Fluchtziels in die Problematik des Ich einbezogen. Dass die hyperänische Metaphysik bei Benn dann auch zur sine qua non des künstlerischen Schaffens wird, zur "Transzendenz der schöpferischen Lust", darauf wird der zweite Teil dieser Arbeit ausfihrlicher eingehen, in dem erörtert wird, dass für Bemn die absolute Kunst, wie er sie auffasst, eine Zuflucht darstellt, und, mit Benns späterem Intellektualjsmus vereinigt, zu einer monologischen Tätigkeit seitens des Künstlexs wird. 
WIRKLICHKETTSERZEUGUNG UND -ZUSAMIENBRUCH

1: Mit dem Vorgang der progressiven Zerebration kausal eng verbunden ist *das Phänomen der Wirklichkeitserzeugung. Als das Ich au denken, die, Umwelt zu prifen, analysieren und sezieren anfing, als sich Ich und Welt voneinander *rennten, ereignete sich "die schizoide Katastrophe, die abendländische Schicktsalsneurose: Wirklichkeit". I Unter dem Ausdruck "Wrrklichkeitserzeugung" wird das verstanden, was in der abendländischen Geschichte im spăten Quartär zur Wildung des logisch-diskarsiven Ich, des begrifflich in Kategorien denkenden Tch beitrug, das heisst, Erkenntnistheorie, Metaphysik, Geschichtsphilosophie, die Naturwissenschaften und, insofern sie die vorgenannten unterstitzten, Religion und Moral. Es galt, dem entwurzelten Ich eine Identität und eine Kontinuität zu geben, ihm eine Beziehung zur Unwelt und zu den anderen Ichs zu verschaffen. Die drei grossen Phasen in der Geschichte der Wirklichkeitserzeugung sind die Epochen der Religion, der Philosophie und der Wissenschaft. Alle drei sind Versuche einer zivilisatorischen Menschheit, dem Ich einen Halt zu geben - die Realität. Zu diesem Zwecke wurde alles analysiert, deriniert, identifiziert, etikettiert und kategotisiert, und eine Sprache wurde dazu geschaffen.

Tine Zeitlang galt die Religion als Grundstein der Realität. Finst wurde jedes Phänomen in der Natur als'Beispiel von Gottes Allmacht und Wunderwirken betrachtet und erklärt. Doch der Glaube entwertete sich als die Wissenschaft und das diskursive Denken damit in Konflikt gerieten. Gott und Götter starben, als die religiöse Erklärung and Rechtfertigung der Dinge mit der Zeit nicht 
mehr hinlangte, und đie Umstellung vom religiösen Ich zum philosophischen Ich erfolgte. Es erwies sich aber auch die Herrschaft des kausalanalytischen Den-

- Jens als ephemer. Das logisch-diskursive Denken in Kategorien machte vor der empirischen Welt halt. Realitas in ente stimnte nicht imner mit realitas in mente überein. Dann ereignete sich die Umstellung zur wissenschaftlick- positivistischen Epoche, zur Epoche der Natur und zur Ipoche Darwins, eine Epoche, die dem Ich, enttäuscht durch Religion und Philosophie, ein letztes Absolutes Wet. Der Zusammenhang zwischen dem Wissenschaftspositivismus und dem durch Yivellierung der Werte daraus erfolgenden Nihilismus ist in ersten Kapitel gieser Arbeit bereits erwhihnt worden. Aljmählich entdeckte man aber, dass die tis Dinge aus dem "seit Kepler für unantastbar gehaltenen mechanischen Wel.tbild" berausgebrochen waren. ${ }^{2}$ Selbst manche der Naturgesetze erwiesen sich als kei-... neswegs allgemeingültig. Die Wissenschaft war sich selbst zum Verhängnis geworden. Kurz, die alten Maßstäbe galten nicht mèr und neue fehlten.

Das Ich, das auf das logisch-diskursive Denken gegründet worden war, verIor seine Grundlage und geriet in ein Vakuum. Mit dem Denken hatte nan' es zu weit getrieben: man hatte die Welt "zerdacht". Das Resultat: ein "verlorenes Ich". Benn ist der Ansicht, dass die grossen Nënner vergangener Jahrhunderte die Unvermeidlichkeit des Wirklichkeitszusammenbruchs voraussahen und es als ihre Aufgabe empfanden, ihren eigenen Nihilismus zu verdecken, "einen Nihilismus, der sich aus den verschiedensten Sphären genährt hatte: dem Religiösen bei Dürer, dem Moralischen bei Tolstoi, dem Erkenntnismässigen bei Kant, dem allgenein Menschlichen bei Goethe, dem Gesellschaftichen bei Balzac." 3 In In dieser Beziehung ist es für unsere Zwecke aufschlussreich, dass Benn Nietzsehes Lehre vom tibermenschen in biologisch-darwinistischem Licht sah und 
Nietzsche vorwarf, sein Zarathustra sei das Ejakulat eines biologisch-darwinistischen Züchtungsoptinsismus. ${ }^{4}$ Dass Nietzsches ẗ̉bermensch keineswegs unter diesem Gesichtspunkt za deuten ist, darauf wird der zweite I'eil dieser Arbeit eingehen. Dass aber Bemn, in seiner sogenannten "Nazi-Periode", selber ein Jünger der Ziiohtungsidee war, sei hier erwähnt, und zwar darum, weil die Enttäuschung darïber wesentlich zu seinem Wirklichkeitszusammenbruch beitrug.

In Benns Antwort auf die Vorwürfe Klaus Manns im Jahre 1933 ist weniger ein Plädoyer,fü den Natiomalsozialismus zu sehen als eine letzte verzweifelte Hoffnung, dessi der Wirkeichlseitszusammenbruch doch nicht endgülig sei, dass es noch irgendetwas gebe, dess dem Abendland noch einen Inhalt, einen Halt böte. 5 Der Brief an Klaus Mann ist romantisch und voll von Schicksalsrausch und Geschichtspositivismus. Ans ihm spricht eine Umstellung zum sozialen Ich heraus, als Benn schreibt, es sei Mein Volk,.. das sich hier seinen Weg bahnt. Wer wäre ich, mich auszusschliessen, weiss ich denn etwas Besseres - nein!" 6 Auch sei darauf hingewĩesen, dass Benn in seinen Aussemungen über Staat und Rasse diese immer in Zusamenhang mit Kunst erwähnt. So schreibt er im Jahre 1934:

Das Leben ist ergebnislos, hinfällig, untragbar ohne firgänzung, es muss ein grosses Gesetz hirzutreten, das ... es richtet ... Es gibt heute zwei Gesetze, die sich in Europa gegen das Leben erhoben haben: die Rasse und die Kunst. Beide silld Forderungen, beide unerbittlich strenge Gesichte, beïde liegen im Geist. 7

Bald hatte Benn aber Bedenken gegen den Nationalsozialismus, bald wurde ihm klar, dass der neue stazt die Kunst nicht schützen, sondern sie verdrängen würde. ${ }^{8} 1938$, als das Schreibverbot iber ihn verhängt wurde, wurde Benn endgültig kJar, dass die thither es mit der Kunst nicht redlich meinten, wenn die Kunst nicht ihren Zwecken diente. Ausserungen friherer Blindheit, Najvitöt und 
unterbewusster Wunschgedanken verklangen, wie: "Fuhrer ist nicht der Inbegriff der Macht, ist überhaupt nicht als Texrorprinzip gedacht, sondern als höchstes geistiges Prinzip gesehen. Fihrer: das ist das Schöpferische ..." 9 und "der Staat macht das Individuum kunstfähig, aber übergehen in die Kunst, das kann die Macht nicht." 10

Warum sịch Benn von dem Nationalsozialismus täuschen liess, ist wohl mit der Behauptung Thilo Kochs zu erklären, dass Benri eben auf eine naive Weise unpolitisch wax, die zwar verhingnisvoll, aber for 1914, als Benn seine Ausbildung genoss, manter Intellektuellen nicht unseIten war. ${ }^{11}$ Gewiss ist jederfalls, dass die Illygionen des Schicksalsrausches schon 1934 verflogen. ${ }^{12}$ schon 1933 war er von einer Liste der Ärte gestrichen worden, die bestimmte Atteste ausstellen durften. Benns Eintritt in die Armee im Jahre 1935, wo er bej der Versorgung beschäftigt war, war eine Art geistige Emigration, eine F'lucht ("Die Armee ist die aristokratische Form der Emigration"). ${ }^{13}$ Von diesem Zeitpunkt an, nachdem er seinen Glauben an den Staat als letzte Hof fnung im allgemeinen Wirklichkeitszusamenbruch abgeschworen hatte, gab es fiux Benn nur noch eines die Kunst. Die Inhalte, die Wahrheit waren verloren; und zwar endgultig. Es gab nur noch die Form und die "formfordernde Gewalt des Nichts", und das Ich musste zu einem Iyrischen Ich werden, musste "das Leben formend überwinden", denn "welches war der. Weg der Menschheit gewesen bis hierher? Sie hatte Ordnung herstellen wollen in etwas, das hätte Spiel bleiben sollen. Aber schliesslich war es doch Spiel geblieben, denn nichts war wirklich." 14 
METAPHYSISCHER VERRAT

Es wurde Benn öfter vorgeworfen, dass er Atheist sei. Das stimmt keineswegs, wenn man unter "Atheismus" Gottesleugnung versteht. An die Existenz eines höheren Wesens hat Benn eigentlich nie gezweifelt, bis zu seinem Lebensende nicht. In einem Brief aus dem Jahre 1952 an Alexander Lernet-Holenia schreibt Benn:

.... niemand jst ohne Gott ... nur Narren halten sich für autochton und selbstbestimmend. Jeder andere weiss, wir sind geschaffen, allex-... dings alles andere liegt völlig im Dunkel. Die Frage ist also gar nicht, ob Gott oder Nicht-Gott, die Frage ist nur, ob man Gott in sein Leben verarbeitet.... 1

Wenn man aber das Wort "Atheist" streng etymologisch interpretiert, so stellt sich heraus, dass im Griechischen die Vorsilbe "a" soviel bedeutet wie "ohne" und das Hauptwort "theos" "Gott". "In diesem Sinne des Wortes wäre ein Atheist jemand, der ohne Gott ist. Zu dieser Kategorie gehörte dann Benn und das "späte Ich", das "verlorene Ich", das nach dem Wirklichkeițszusammenbruch im Vakuum zurickblieb. In dem Brief an Holenia fährt Benn fort, er finde Gebet. und Demut arrogant und frevelhaft, denn es setze voraus; dass der Mensch überhaupt etwas für das grosse Wesen bedeute, was aber nicht der Fall ist.

Der metaphysische Verrat und die Enttäuschung bestehen Benns Ansicht nach daraus, dass dem abendländischen Nienschen jahrhundertelang ein Iiebender, väterlicher Gott, der sich um inn kümmert, und ein Jenseits unterschoben wurden. Die Erfahrungen der Jahrhunderte und der Wirklichkeitszusammenbruch hatten aber bewiesen, dass der Mensch allein und auf sich selbst angewiesen ist. Kurz, "man hat uns belogen und betrogen / mit Gotteskindschaft, Sinn und 
Zweck." ${ }^{2}$ In einem Brief an Edgar Lohner schildert Benn diese Lage, indem er den Ausdruck "Eigen-Jnnortelle" in dem Gedicht "Das späte Ich I" erklärt. Das späte Ich, schreibt er, lebe nur in sich selbst und erlebe nur sich selbst. Dies sei seine extreme Lage. Auch die Unsterblichkeit ende für dieses Ich nit dem Tode: die allgemeine Immortalität sei ein aus Wohlwollen und Todesangst geprägter Begriff. 3

Die Leere und Einsamkejt des vercatenen späten Ich, dem die traditionelle 4 Transzendenz und der Glaube entzogen wurden, beschreibt Benn, den dies als Pfarrerssohn besonders schwer erschïtert haben mass, in einem stiuck aus dem Jahre 1913:

Jahre waren es, die lebte ich nur im Echo meiner Schreie, hungernd und auf den klippen des Nichts ... Früher in meinem Dorf wurde, jedes Ding nux mit Gott oder dem Tod verknüpt und nie mit einer Irdischkeit. Da standen die Dinge fest auf jhrem platze und reichten bis in

das Herz der Irde. Bis mich die Seuche der Erkenntnis schlug... Da

* Fongen die Dinge an zu schwanken, wurden verächtlich und kaum des Ansehens wert. Und selber die grossen Dinge ... 4

Es sei hier nicht zu verkennen, dass es die Erkenntnis ist, die die Inhalte geschaffen hatte, die, infolge der Zerebration, dieselben Inhalte zerstört hat. Das Denken wandte sich auf sich selbst zuriick. Eine Transzendenz oder einen metaphysischer Grund der Dinge gibt es im traditionellen sinne nicht mehr. In einem kurzen Stück aus dem Jahre 1931 weist Benn auf seinen aus dem Vaterhaus geerbten "Fanatismus zur Transzendenz" hin, die für ihn jeden platten Materialismus psychologischer oder historischer Art für die Darstellung des Jebens unzulänglich macht. 5 Im allgemeinen Nihilismus der Werte aber sehe er keine andere Transzendenz als die der schöpferischen Lust, die der Kunst. Dass mit diesen Worten keine ausserhalb der Moglichkeit des Erkennens liegenden, die Grenzen der Erfahrung iberschreitenden Prirzipien, also keine Transzendenz und 
keine Metaphysik im traditionellen, im christlich-platonischen Sinne des Ausdrucks gemeint wird, liegt ouf der Hand. Gemeint wird vielmehr eine Transzendenz it Sinne von "ubersteigen". Benns Transzendenz, die für seine Theorie der

- Asthetik wesensbestimmend ist, bedeutet ein Übersteigen des Bewusstseinszu: standes und der Gespaltenheit des Ich in die hyperämischen Zustände, eine "Buickkehr des späten Ich zu der "frühen Schicht" des Bewusstseins, ${ }^{6}$ zu dem Urszustand (Urgesicht), der ja als Dauerzustand nicht mehr möglich ist, den aber Wdie organische Masse, dessen Funktion Geist und Persönlichkeit sind, 7 als Erbmasse fruherer Zeiten in sich trägt. Der Zustand, zu dem das späte Ich zeitweilig wie zu einem Zufluchtsort zurückkehren kann, ist zugleich die quelle des artistischen Schaffens, die "Transzendenz der schöpferischen Iust". 
- Die Repräsentanten des späten Ich in Benns Prosa sind die Ärzte Rönne fund Pameelen. Beide verkörpern die Zersetzung einer Epoche, denn in ihrem Hirn * zerfällt, und zwar endgii,tig, das Begriffliche, das Logische, das viele JahrWhunderte geprägt hatte. Die Grundlage, auf die das Ich, die kontinuterliche

SPsychologie, aufgebaut worden war, gilt nicht mehr. Folglich gibt es nichts mehr, das es trägt. Das Ich ist zerfetzt.

1. Die Symptome des zerfetzten Ich sind Kontaktverlust, Weltverfremding, Werhaltensunsicherheit, Realitätszerfall and Befrenden vor dem Alltägilchen. "Rönne, der Arzt ... das nackte Vakuum der Sachverhalte, der keine Wirklichkeit ertragen konnte, aber auch keine nehr erfassen", ${ }^{1}$ ist ein Schrei nach einer Identität: "Ein Drängen nach dem Sinn des Daseins warf sich ihn wiederhoIt entgegen", 2 aber es gibt keinen Sinn mehr, nur dessen Bruchstücke. Rönne hatte früher viel seziert - ungefähr zweitausend Leichen sind durch seine Hände gegangen - und ist auf eine merkwiirdige Weise erschöpf.t. Zusammenhänge fehlen: es bleibt nur noch das Mechanische, wie die Bewegung seiner Hände, wenn sie die zwei Hälften ejnes Gehirns auseinander biegen, eine Geste, die zur Gewohnheit geworden ist, die er in den Gängen des Krankenhauses macht, unbewusst und fast tickhaft. Er will eine Reise untemehmen, zweifelt aber daran, dass das Unternehnen irgendeinen sinn für ihn haben kann, denn es fehlt an einem bedeutungsvollen Verbältnis zwischen ihm und der Unwelt. Der Triumph, den er im Kasino erlebt, als "aus jedem der Mitesser inm der Mitel eines Herm zustieg, der nach der Hahlzeit einen kleinen Schnaps nicht verschmähte und ihn 
mit einem bescheidenen Witzwort zu sich nimmt", 3 begleitet Rönne bis zur Tür, weiter nicht.

1. Das kontinuierliche Ich und seine Weltanschaung hatten sich also entwirklicht und mit ihnen die Sprache. Rönne widmet sjeh der Schaffung einer neuen Syntax. Da der Kontakt zwischen Ich und Du fehlt, gilt es, den Du-Charakter der Grammatik auszuschalten. " 4 Die Anrede ist mythisch geworden". 5 Ähnlich ist die Lage des Arrtes Pameelen, in dem der Drang nach Definition triebhaft wird. Er heisst "Vermessungsdirigent", da es aber nichts mehr zu vermessen gibt und alle Maße fèlen, ist sein Untemehmen sinnlos. Sowoh]. Hfiur Rönne als auch für Pameelen bleibt die kontinuierliche Psychologie ventoren. Beide aber finden den Ausweg aus sich selbst ins formale. "In diesem grundlegenden Gefül für die anthropologische Erlösung im F'ormalen ... beginnt die neve Epoche, das neue Notwendige ... beginnt die Ausdruckswelt." 6 
DIE ANTINOMIE VON GEIST UND IIEBEN

In "Lebensweg eines Intellektualisten" heisst es:

Der Mensch hat einen getribten BIick rückwärts, vorwärts gar keinen. Er ist ja nur ein halbgelungenes Wesen, ein Entwurf, das Werfen nach einem Adler, schon riss man die Federn, die Flügel nieder, aber die, ganze Gestalt schlug noch nicht um - wird sie einmal umschlagen, so dass ihr Herz unmittelbar am Herzen der Dinge mht? I

$\checkmark$ In den Reden und Essays Bemns befinden sich zahlreiche Ausserungen dieser Art. Es scheint zunächst, als wollte Benn gegen den Menschen und gegen das leben anhgehen. Fragt man sich aber, worin diese scheinbare Polemik gegen den Menschen "und das Ieben besteht, so stellt sich heraus, dass Benn darunter die cespaltenheit des Menschen meint, die Antinomie von Geist und Leben.

Des Wort "Leben", das für den jungen Autor der Morgue-Gedichte mit dern Biologischen identisch war, nimmt fü den älteren Benn eine erweiterte Bedeutung an, und schliesst die von der zivilisatorischen Menschheit durch Jahrhunderte geschaffene "Wirklichkeit" mịt ein. Mit dem Vexlust der prälogischen Einheit der primitiven Wenschheit und nach dem gescheiterten, Versuch der religiösen Epoche, den Menschen als Einheit von Leib und Seele, allerdings unter Vorherrschaft der Seele, auszugeben, kan die bittere Erfahrung; dass es diese Einheit nicht mehr gibt. Diese Erfahrung gibt Añass zu Aussagen wie die des Ptolemäers:

Das Ieben - dies Speibecken, in das alles spuckte, die Kihe und die Wirmer und die Buren -, das Leben, das sie alle frassen mit Haut und Haar, seine letzte alödheit, seine niedrigste physiologische Fassung als Verdauung, als Sperma, als Reflexe - und das nun noch mit ewigen Zwecken serviert .... 2

Der Mensch ist kein höheres Wesen, betont Benn immer wieder, vielmehr ein hoch- 
gekämpftes Wesen, das in Laufe seiner Entwicklung entartet ist. 3 Das Leben, mit den letżten Fetzen der "Wirklichkeit", die nach dem Zusammenbruch übriggeblieben sind, geht weiter, aber der Geist ist ein Trieb nach Definition.

Es ist unmöglich, Geist und Leben zu versöhnen. "Das, was lebt, ist letwas anderes als das, was denkt." 4 Die Frage wäre nun, wie man mit dem unüberbrückbaren Gegensatz von Geist und Leben leben kamn oder soll. Die Antwort darauf ist das "Doppelleben" des Ptolemäers, der sich mit der schizoMatenen Gespaltenheit des Menschen, mit der Antinomie von Geist und Feven hit nur abfindet, sondern ein bewusstes, systematisches Auf spalten der Persinlichkeit betreibt, eine Selbstaufspaltung. Der Ptolenäer, Leiter des Instituts "Lotos" ("Körperpflege einschliesslich Krampfaderm) lehnt "Gesamtschau, Tothitätsbetreuung, Lebenseinheit [und] Harmonie" ab: "Wir alle leben etwas" anderes, als wir sind. Dort wie hier Bruchstücke, Reflexe; wer Synthese sagt, ist schon gebrochen." 5 Durch die Technik der Aufspaltung wird dem Ptolemäer unbegrenzte geistige Ereiheit möglich: er gewinnt Spielraum für die Entstehung der künstlerischen Formen, die der Drang der expressiven Kräfte exfordert. "Das Geschäft und die Halluzinationen", ${ }^{6}$ sagt der Ptolemäer. "Er will sagen, Geist und Leben sind bei mir zwei völlig getrennte Welten, ich bearbeite die Dame, aber in mir ist oktoberfest". " So lebt er hin: aussen verdient er sein Geld und innen hat ex einen Hohlraum für die Gebilde, füx die Intstehung der Formen. Die Lage erkennen, sich damit abfinden, heisst es. Jeder Versuch, eine Finheit zwischen Geist und Ieben herzustellen, muss scheitera, denn sie sind unversöhnbar. Jenseits des "Lebens", der Wirklichkeit aber beginnt das Reich der geistigen Formen, der hinterlassungsfähigen Gebilde - der Kunst. Alles andere ist fragwürdig und iberheblich. 


\section{DAS BIONEGATIVE}

* Der Begriff des Bionegativen, ${ }^{1}$ oder dessen, worauf manche Autoren als

"die "bionegative Haltung" hinweisen, 2 ist wesentlich fuir das Verständnis von

Benns Auffassung sowohl der Antinomie von Geist und Leben als auch der von

Kunst und Leben. "Bionegativ", ein Begriff, der von dem Psychologen und Pathographen Wilhelm Iange-Bichbaum geprägt wurde, umfasst:"

... alles, was unginstig abnorm ist hinsichtlich der Lebensfundtionen und (oder) der Nachkommenschaft. Also Missbildungen, Entwiokliangshemungen, ungunstige Variationen (sant ihres Vererbbarkeit) und schliesslich, als die extremste Unterabteilung, alles ausgesprochen Kränkliche oder Kranke. 3

demeint wird hier nicht das Abnorme schlechthin, denn schliesslich gibt es auch das biopositiv Abnome, sondern Minusvarianten, ob im psychischen Bereich (Teurosen und. Psychosen) oder im somatischerl.

Mit dem Thema des Bionegativen beschätigt sich Benn in dem aus dem Jałre 1930 stammenden Essay "Das Genieproblem". Nach Aufzählung der grossen Kinstler und Denker, die eine psychische oder somatische Differenziertheit aufurejsen, verknüpft der das Bionegative mit dem genjal Produktiven in der Formulierung: "Genie ist eine bestimmte Form reiner Entartung unter Auslösung. von Produktivität." 4 Dass für Benn die Persönlichkeit, das Geistige und das Geniale Funktionen der organischen Masse sind, ist bereits erwähnt worden. 5

Obwohl Benn aber eine Art Theorie von physiologischem Deterninismus aufstellt, lehnt er die funktionelle winheit von Körper und Geist, das Ideal von mens sana in corpore sano, insofern es die Auslösung gejstig-schöpferischer Ieistungen betrifft, nachdrücklich ab. Der Geist und seine genialen Leistungen, 
behauptet Benn, hängen nicht von der Gesundheit des (physisch oder somatisch) Biologischen ab (eher das Gegenteil). Vielmehr nirmt der Geist eine dem Leben übergeordnete, eine das Leben transzendierende Stelle ein.

Nun wäre die Frage berechtigt, wie sich das Bionegative, das das Leben schädigt, zur genialen Produktivität verhäl,t. Nach Benn gibt es kein völilig - gesundes Genie. Hier sei aber unterstrichen, dass weder Benn noch Lange-Eich* baum an das Pathologisohe als die schlichte Ursache genialer Schöpfung und Produktivität glauben. Schliesslich gibt es genug Alltagspsychopathen und h-alkoholiker, und Taube, die nie eine Symphonie komponieren werden. Talent, * das wie die physischen tigenschaften vererblich ist, blejbt immer vorauszusetzen. Wenn aber Talent vorhanden ist, fördert das Bionegative die geniale Produktivität, indem es als Antrieb zum Schaffen wirkt und eine Spannung herstellt, die conditio sine qua non des Schaffens. Dieser Spannung, die eine Spannung zwischen Innen und Aussen, Geist und Leben, Individuum und Gesell-schaft, zwischen Norm und Abnorm ist, können innere sexuelle Konflikte, ejne wirklichkeitsfremde Phantasie, ein abnormes Geltungsbedirfnis, oder eị pathologischer Minderwertigkeitskomplex zugrunde Iiegen - ob als Begleiterscheinungen physischer Krankheiten oder ohne sie - oder aber auch pathologische Zustände toxischer Art (Alkohol, Rauschgift). Die Hauptsache ist die dadurch entstehende Spennung, denn je grösser die Spannung, desto dringender ringt sie nach Entladung, nach Ausdruck. Das Bionegative ist also als Reiz zum genialen Schaffen zu verstehen, und das Produkt, das dadurch entsteht, entsteht nicht trotz des Bionegativen, sondern mittels des Bionegativen, das die Funktion eines Katalysators ausübt. so ist das Paradox zù erklären - so wird das Negative im biologischen Bereich im geistigen positiv ausgenützit. Was also 
dern Leben schadet, kann (miss aber nicht) der genialen Produktivität dienen. Das Bionegative und die Spannung, die daduroh entsteht und nach Ausaruck ringt, gehöten zurn Wesen der hyperämischen Metaphysik Benns. Das ist folgendermassen zu erklären: infolge der progressiven Zerebration ist, wie wir bereits gesehen haben, der Geist in die Isolierung gedrängt worden, und heine Antinomie zwischen Geist und Ieben ist entstanden, wegen deren die Einheit der prälogischen Geistesart als Dauerzustand für den heutigen Menschen Gicht mehr erreichbar jst. Die hycerämischen Zustände aber - Traun, Rausch tind manche Geisteskrankheiten - sargen für eine Lockerung der Ratio, die oft Jerstarrt und infolgedessen kunstschädrich ist. 6 Die gelockerte Ratio fordert das geniale Schaffen durch Enthemmung, Ideenflüssigkeit und vermehrte Einfälle. Dieser Zusammenhang zwischen dem Pathologischen und dem genialen Schaffen, der der Lehre des Bionegativen zugrunde liegt, kommt in den Schriften Benns häufig zum Ausdruck. "Nàch geistigen Maßstäben", schreibt er in "Provoziertes Leben", hat der extravagante Körper mehr geleistet als der normale, seine bionegativen Eigenschaften schufen und trager die menschliche Welt. Vor diesen Maßstäben gibt es iberhaupt keine Wirklichkeit, auch keine Geschichte, sondern gewisse Gehirne realisieren in gewissen Zeitabständen ihre Träume, die Bilder des grossen Urtraums sind, in rückerinnerndern Wissen. Diese Realisation vollzieht sich in "Stein, Vers, Flötenlied", dann entsteht Kunst; manchmal nur in Gedanken und Ekstasen. 7

Dass Benn aber die Kunst selbst unter die bionegativen Werte rangiert ("Werte ... die die Rasse eher schädigen und sie gefälirden, die aber zur Differenzier ung des Geistes gehören, die Kunst, das Geniale, die Auflösungsmotive des Religiösen, das Degenerative... " ${ }^{8}$ ) ist schon eine Vorqusdeutung der Antinomie von Kunst und Leben, die für Benns Ästhetik ausschlaggebend ist. Das Verhätnis zwischen Kunst wnd teben wird im zweiten Teil dieser Arbeit untersucht. 
NIETZSCHE UND DER EUROPÄISCHE NIHILISMUS

DECADENCE UND ENTWERTUNG DER BISHERIGEN HÖCHSTEN WERTE

In seiner Vorrede zum "Willen zur Macht", in der er die Geschichte der wächsten zweihundert Jahre als die Heraufkunft des Nihilismus prophezeit, 3 nennt sich Nietzsche den ersten vollkommenen Nihilisten Europas, "der aber den Nihilismus selbst schon in sich zu Ende gelebt hat, der whn hinter sich, ! unter sich, ausser sich hat." " Diese Einfuhrung und der Untertitel des oben erwäknten Werkes - "Versuch einer Umwertung aller Werte" - deuten schon auf Nietzsches Einstellung zum Phänomen des Nihilismus voraus. Nietzsche, der Philosoph des Werdens, betrachtet die décadence (d.h. die traditionellen. höchsten Werte des Abendlandes), den Nihilismus und die Epoche der neuen Werte als kausal und chronologisch verbunden. Die Umwertung setzt den Nihilismus notwendig voraus und erfolgt aus ịm, genau wie der Nihilismus die décadence voraussetzt und aus ihr hervorgeht. Die drei Phänomene bilden oine Kettenreaktion, in der die décadence als der Pränihilismus und die Umwertung als der Postnihilismus zu verstehen sind, und der Nihilisnus als historische Ananke in Mittelpunkt steht, denn in ihm ziehen die bisherigen Werte ihre letzte Folgerurig. Un den Nihilismus von dem Gesichtspunkt der letzten Folgerung aus der décadence zu betrachten, muss man nach dem Wesen und der Intstehung dex décadence fragen. Décadence bedeutet für Nietzsche die bisherige abendIändische Betrachtungsweise und Wertinterpretation des Daseins. Décadence ist ein Kollektivbegriff und umschjiesst für Nietzsche die Religion, die Moral und 
die Philosophie. Es sei nìcht verkannt, dass Nietzsches Ansicht nach die Betrachtungsweise des Daseins von der Perspektive der christlichen Religion urld Moral und der platomisch-chritlichen Philosophie aus mit décadence gleichzusetzen ist, dass also diese Religion, Moral und Philosophie von der Zeit

1. ifirer Fintstehung an dekadent waren, nicht etwa, dass sie nach einem gesunden Anfang im Jaufe der Zeit entartet wären. Die Gültigkeit dieser Behauptung istellt sich bald heraus, wenn man Nietzsches Erörterung über die Intistehang Gieser dekadenten Wel tanschaung in Betracht zieht.

* Eines der bedeutemdsten Thenen in den Schriften Nietzsches ist die. Gegeniuberstellung der gexiffe "stark" und "schwach", "mächtig" unf "machtlos", "gesund" und "krank". Dabei ist es aufschlussreich, dass für Nietzsche wischen den gegenibergestellten Begriffen nicht nur ein quantitativer, sondexn auch ein qualitativer Unterschied besteht. Einer, der schwach, machtlos, oder dekadent (bzw. krank) ist hat nicht nur weniger Stärke, Macht und Gesundheit als der Starke, Machtige und Gesunde, sondern etwas, das sich seinem Wesen nach von Stärke, weht und Gesundheit radikal unterscheidet. Der Beweis dafür sei die. Tatsache, dass der Schwache ganz anders handelt als der Starke: dieser mit Rücksicht und nach Erwägung der Situation, jener aus Angst, aus Not, oft ohne Erwägung Folgen. Das Handeln des Schwachen ist oft voreilig und fast inmer ich-bezogen. Der Schwache ist sich seiner Leere und Ohnmacht allzusehr bewasst und bendelt aus Ressentiment. Was er tut, richtet fast immer Schaden an.

Nietzsche erörtent den Ursprung der christlichen Moral und Religion, gegen die er wegen ihrex Dekadenz polemisiert, in den Werk "Zur Genealogie der Moral ausfihrlich und get dasselbe Theme in seinen anderen Schriften immer 
wi.eder auf. In der "Genealogie" wird das Phänornen des Ressentiments als Quelle der christlichen Religion bezeichnet. Ressentiment ist eine Gemitsverfassung der Schwachen, Machtlosen und Schlechtweggekormenen, die zwei Aspekte aufweist. Erstens ist es ein Bewusstwerden der eigenen Schw:żche und Nichtigkeit und der Stärke und Macht der anderen, zweitens ein Handeln aus

Rachsucht, wodurch der Schlechtweggekomnene seine eigene Lage zu bessern versucht, wenn auch zum Schaden anderer. Dieses Handeln ist weniger eine Aktion als eine Reaktion - ein Handeln gegen etwas oder jemanden. Die christliche Religion, die Religion der Itilde und der Demut, des Jenseits, des Gekreuzigten, des Leidens und der Askese ist Nietzsches Ansicht nach die geistige Revolte der Sklaven gegen ihre Herren, die eine absoIute Macht und infolgedessen auch Druck auf die Sklaven ausibten. Die Herren hatten Macht und Reichtum, die Sklaven hatten nichts und mussten noch die

Horren bedienen, arbeiten und die grausamste Behandlung ïber sich ergehen lassen. Kebellion kam gar nicht in Frage. Aber die Sklaven rächten sich: sie erfanden die Religion der Schwäche, mit Milde und Demut als Tugenden und Machtausibung, wie Diebstahl und Nord, als Sinde. Anders konnten sie sich gegen die Mächtigen nicht wehren. Sie erfanden das Jenseits - das Himelreichwo sie, die Milden und Schwachen belohnt werden, und die Hölle, wo die Mïchtigen, die es auf der Erde gut hatten, bestraft werden sollten, und das in alle digkeit. Da das Leben diesseits ephemer ist, das jenseitige aber ewig sein soll, wurde das piesseits als nichtig betrachtet, und die Moral mit ihrem "Du sollst nicht" konnte Fuss fassen.

Die Moral, warde zum Maßstab des Lebens und der "gute Hensch" zum Ideal. Aber der "gute Mensch", der "gut" genannt wird, weil ex in Wirklichkeit zu 
schwach ist, böse zu sein, ist eigentlich nur der ideale Skjave. Dieser ideale Sklave wollte aber; dass alle anderen "gut" (d.h. schwach) werden, denn nur dann ist er selbst beschiitzt.

Man fragt sich, inwiefern das Christentum und die Moral als décadence betrachtet werden können. Verfolgt man das Wort dẻcadence etymologisch zuauck, so stellt sich heraus, dass es im Lateinischen "decadere" heisst, also "therunterfallen von", man könnte auch sagen "Niedergang" oder "Untergang". Mas diesseitjge Leben and dex aussergewöhnliche Mensch komen zu kuxz dabei, Aenn Sklaven-Mabstäbe Herden idealisiert. Deshalb betrachtet Nietzsche $\therefore$

13. das Christentum als die vexhängnisvollste lüge der Verfuhxung, die es bisher gegeben hat, als die grosse unheilige Liige.... Di.e KIejnelieute-Moralität als $\mathrm{MaB}$ der Dinge: das ist die ekelhafteste Entartung, welche die Kultur bisher aufzuweisen hat. 2

Herdenmoral wurde zur Moral schlechthin.

Nach der Religion und Moral ist das dritte grosse décadence-Symptom, mit dem sich Nietzsche auseinandersetzt, die Philosophie, und zwar die Philosophie von Sokrates an. ${ }^{3}$ Diese Auseinandersetzung beruht auf der Meinung, dass die Philosophen die gxündlichste Art Heimweh und Romantik vertreten, die es je gegeben hat. ${ }^{4}$ Nietzsche klagt die Philosophen der christlich-platonischen Tradition weger Eingenormenhej.t "gegen den Schein, den Wechsel, den Schmerz, den Tod, das Körperliche, die Sinne, das Schicksal urid die Unfreiheit, das Zwecklose" an. " Die Philosophen, behauptet Nietzsche, verewigen -die in der "Götzendämmerung" erwähnten vier grossen Irrtïmer: die Verwechselung von Ursache und Folge, die falsche Ursächljchkeit, den Irrtum der imaginären Ursachen (Gott, das Ding-an-sich) und den freien Willen. 6 Unter dem Gesichtspunkt dieser Philasophie gesehen werden das Leben, das Körper- 
liche und das Sinnliche verneint, denn in Grunde dient die christlich-platonische Philosophie der Religion und Moral und unterstitzt sie.

Die Philosophie, die Religion und die Moral, die im Ather das Ding-ansich suchen, die den Willen frei machen, um den Menschen schuldig machen zu können, die den Geist isolieren und Körper und Sinne verleumden, münden notwendigerweise im Nihilismus, denn Nihilismus bedeutet, dess die "obersten Werte sich entwerten". ? Diese Entwertung ist unumgänglich, denn die bishertogen horchsten Werte sind die reinste Unnatur. Is ist bereits erwähnt worden, dass der Nihilismus als die letzte logische Folgerung der bisherigen obersten Werte zu verstehen jst. Die Keligion, die Moral und die Philosophie haben von threr Entstehung an ihren Untergang in sich getragen, obwohl sie sich erst neuerdings als endgültig unhaltbar erwiesen haben. Es ist die Wahrhaftigkeit, dìe so sehr gepriesen wurde, und das logische Denken der Philosophie, die sich auf sich selbst zurückgewandt und, als ihre letzte Konsequenz, den Glauben an die alten Werte zerstört haben. 
DIE AXIOLOGISCHE AUSEINANDERSETZUNG:

DIESSETTS UND JENSEITS-

POLEMIK GEGEN DIE METAPHYSIK

Einer der Unterschiede zwischen der Einstellung Benns und der Nietzsches ma der allgemeinen Grundlagenkrise, die der Nihilismus, die Entwertung der Wisherigen höch'sten Werte mit sich gebracht hat, ist, dass sich Bern mehr oder Weniger mit der Lage abfindet, die verlorenen Werte verjoren sein lässt, Ieben and Geist und Leben und Kunst vomeinander trennt, und schliesslich in der Kunst feinen zufluchtsort sieht. Fir Nietzsche ist das durchaus nicht der Fall. Wie Benn, so erkennt auch er die Lage und betrachtet die bisherigen höchsten Werte als endiültig verloren. Br fasst aber diese Entwertung und den Nihilismus als eine logische und historische Notwendigkeit auf, als die Vorstufe der neuen Wertsetzung, die seine Philosophie der Menschheit geben wil. . Fir Nietzsche gilt es, den letzten Resten der alten Werte den coup de grace zu geben, - die erste Phase -, damit die Umwertung - die zweite Phase -, beginnen kann. Während Benn "Nach dem Nihilismus" die "gezilchtete Absolutheit der Form" sieht, deren "Grade an linearer Reinheit und stilistischer Makellosigkeit allerdings nicht geringer sein dirften als die inhaltiichen frijherer Kulturepochen", bemiht sich Nietzsche un eine Umwerting, die eine radikale Antithese zu der décadence darstellt, eine Wertsetzung, die anthropozentrisch ist, dje den Menschen zum Sinn der Erde und zum Maßstab der Dinge macht und das Leben diesseits zu vol.Ier Geltung bringt.

In den Schriften Nietzsches kommt seine Polemik gegen die Metaphysik oft und heftig zum Ausdruck. Was hier gemeint ist, jst Metaphysik im Simne der 
Lehre von den jenseits der Erfahrung liegenden Gründen der Dinge, also Metaphysik im Sinne der christlich-platonischen Tredition. Diese Metaphysik, die Nietzsche mit Dogmatik - Glaubenssätze, deren Voreussetzungen man nicht prï-: fen kann - gleichsetzt, lehnt er kategorisch ab, wie er die décadence und den Glauben an die ideale Welt des Jenseits ablehnt, und zwar unter einem zweifachen Gesichtspunkt.

Unter der Optik der Wahrheit lehnt Nietzsche des Jenseits und die christMich-platonische Metaphysik ab, weil sie im Grunde eine Iüge darstellt. Wir. haben bereits den Ursprung der Woral und der Religion betrachtet und festgestellt, dass Religion, Moral und Jenseits die Erfindung der Schwacher; Misstatenen und Schlechtweggekommenen sind, eine Erfindung aus Ressentiment und Schodenfreude, aus einem krankhaften, unterdrückten Willen zur Necht. Nan erfand, man erlog eine ideale Welt, heisst es in "Ecce Homo". 2 Der Glaube an diese ideale Welt ist ein Irrtum, aber nicht aus Blindheit, sondern aus Feigheit. ${ }^{3}$ Zur Psychologie der traditionellen Metaphysik als Wunscherfüllung schreibt Nietzsche im "Willen zur Macht":

Diese Welt ist scheinbar: folglich gibt es eine wahre Welt; - diese Welt ist bedingt: folglich gibt es eine unbedingte Welt; ....diese Welt ist werdend: folglich gibt es eine seiende Welt .... Zu diesen SchIüssen inspiriert das Leiden: im Grunde sind es Winsche, es nợchte eine solche Welt geben; ebenfalls drückt sich der Hass gegen eine Welt, die leiden macht, darin ous, dass eine andere imaginiert wird, eine Wertvollere: das Ressentiment der Ifetaphysiker gegen das Wirkw. liche ist hier schöpferisch. 4

Unter dem Gesichtspunkt des Lebens werden die Metaphysik und das Jenseits abgelehnt, weil das Diesseits danit verleumdet wird. In den Worten Heideggers: "[Die] alte Wertsetzung ist ... die Abwertung des hier und jetzt vorhendenen Seienden ... als desjenigen, was eigentlich nicht sein sollte, weil es ein Abfall vom eigentlich Seienden, von den 'Ideen' und der göttlichen 
Ordnung darstellt ..." 5 we sehr es firr Nietzsche auf das Leben diesseits ankornt, zeigt sich in der Hëufigkeit, mit der das Wort in seinen schriften fäjlt. Der volle, Titel der zweiten der "Unzeitgemässen Betrachtungen" heisst "Vom Nutzen und Nachteil der Historie für das Leben". In der "Geburt der Tragödie" wird die Frage gestellt: "Was bedeutet, unter der Optik des Lebens gesehen, die Moral?" 6 Wie wir in einen späteren Kapitel sehen werden, sieht Nefzsche die Kunst, von der ex behauptet, sie rechtfertige das Dasein und die welt, in der Funktion einer Verfuhrerin zum Leben. Allerdings ist das Letegen, das von Nietzsche so oft gepriesen wird, ein erhöhtes Leben, genau wie dequensch, von dem er sagt, er solle zum Sinn der Frde werden, der tibermensch ist. Die Vorstufe zum erhöhten Leben ist aber das natiurliche, diest : seitabezogene Leben. Dieses diesseitsbezogene Leben meint Nietzsche, wenn er von den Heiden spricht und ihr Leben als Natur der Unnatur der christlicher Ära gegenibersteilt:

Die Geschlechtlichkeit, die Hexrschsucht, die Lust am Schein und am: Betriggen, die grosse freudige Darkbarkeit für das Leben und seine typischen Zustände - das ist am hej.dnischen Kultus wesentlich und hat das gute Gewissen auf seiner Seite. - Die Unnatur.... kämpft gegen das Heidnische an, als Moral, Dialektik."7

Bevor der Mensch zum Sinn der Frde werden kann, muss den "Wexächtern des Leibes", den "Hinterweltiern" und denjenigen, die aús dem Menschen ein krankes Tier gemacht haben, der Krieg erklärt werden. Anstatt on dje weele zu glauben, soll der Merisch an seinen Körper gleuben. Anstatt an den Tod und das Übersinnlicke, solI er an das leben und an die sinne denken. "Wir wollen unsere Sinne festhalten und den Glauben on sie ... Die Widersinnlichkeit der bisherigen Philosophie als der grösste Widersinn des Menschen", schreibt Nietzsche. ${ }^{8}$ Das schlechte Gewissen, mit dem die Religionen den 
Menschen belastet haben mit ihrem "es ist alles schlecht und böse", soll ihm geriomen werden, denn diese "Verurteilung des ganzen Prozesses kann nur ein Urteil von Missratenen sein." 9

Das Christentum mit seiner Metaphysik ist nach Nietzsche das grösste Hindernis für den Übermenschen, für den Menschen wie ex sejn soll, denn wie wir bereits gesehen haben, ist das Christentum die Religion der Anbetung der umgekehrten Werte (Schwäche, Milde und Dernut) und der Nivelilierung der Werte. Alle soljen gleich werden; d.h. gleich schwach, gleich fügsam, gleich kränklich, damit sie in die Herde hineinpassen, denn die christliche Moral ist eine Herdermoral, die keine Ausnahme duldet. "Christlich ist der Hass gegen den Geist, gegen Stolz, lhut, Freiheit, Libertinage des Geistes ..." heisst es in der Streitschrift gegen das Christentum, "Der Antichrist", 10 denn "das Christentum will über Raubtiere Herr werden; sein Mittel ist, sie krank zu: machen, - die Schwächung ist das christliche Rezept zur Zähmung, zur AZivilisation" ". ${ }^{11}$ Ein schwaches, krankes Raubtiex, dessen Instinkte tot sind, ist sowoht ungefährlich als auch fügsam.

An dieser Stelle wäre ein Wort über Nietzsches Auseinandersetzung mit Wagner nicht unangebracht, denn diese Auseinandersetzung beruht zum Teil darauf, was in Bezug auf décadence und den Glauben an ein Jenseits als ein Attentat auf das diesseitige Ieben gesagt worden ist.

In "Nietzsche contra Wagner" vergleicht Nietzsche die christliche Moral mit Wagners Musik und zieht einige Parallelen. Beide, behauptet er, gelten als der Wille zum Ende, zum Untergang, beide nivellieren und betäuben, und beide setzen eine Verarmung des Løbens voraus, die sie dann nicht heilen, sondern zu ihren Zwecken ausnützen. Jede Kunst und Philosophie, meint rietzsche, 
setzt Leiden und Leidende voraus. Diejenigen, die an einer Überfülle des Lebens leiden, sind stark genug dazu dass sie eine Kunst mit tragischer Einsicht in das Leben ertragen können. Diejenigen dahingegen, die an der Verarmung des Iebens Ieiden, haben ein Doppelbedürnis - nach Stille und Ruhe einerseits, und andererseits nach Betäubung. Diese Betiubung wird ihnen in Bayreuth geliefert, wo das Individuum in der Masse ertrinken und versinken kann, wo er in dem schwebenden All und in dem wogenden schall seine höchste Lust in der Unbewusstreat empfindet, wenn er mit den anderen Wagnerianern betäubt wird, 12 Werm nach Bayreuth geht, schreibt Nietasche, verzichtet man:

... auf das Recht der eigenen Zunge und Wahl, auf seinen Geschmack, selbst auf seine Tapferkeit ... Im Theater wird mon Volk, Herde, Weib, Pharisäer, Stimuieh, Patronatsherr, Idiot-Wagnerianer: da unterliegt auch nock das persönlichste Gewissen dem nivellierender Zauber der grossen Zahl ... 13

Wix haben bis jetzt die allgemeine Grundlagenkrise ausgelegt, mit der sich Benn und Nietzsche auseinanderzusetzen hatten, die häufig als Nihilismus bezeichnet wird. Dass es im Gmunde dieselbe Krise ist, dieselben Werte, die sich entwertet haben, liegt auf der Hand. Benn und Nietzsche unterscheiden sich aber voneinander, und zwar radikal, in ihrer Stellungnahme zu der Krise und in den Folgerungen, die sie daraus ziehen.

Wie wir gesehen haben, ist Nietzsches zukunftsbezogenes Denken schon über den Nihilismus hinams und zielt auf die Festsetzung neuer Maßstäbe, die den ganzen Menschen (Körper und Geist) zur Geltung bringen sollen. Fir Nietzsche ist die Intwertung der bisherigen Werte die logische Konsequenz dieser alten Wertsetzung, und die Erkenntri,s, die ihren Niedergang und Untergang in die Wege geleitet hat, soll gur Schaffung der neueri Werte dienen. Nietzsche 
trauert nicht über den Verlust der alten Werte, denn sie waren sowieso falsch und hatten nur den Menschen geschwächt und dabei seine Entwicklung aufgehalten.

Fir Benn ist die Frkenntnis eine "Seuche" (vgl. "Heinrich Mann. Ein Untergang", III, S. II81), mit der alles iris Schwanken geriet. Nicht nur, dass die alten Werte endgültig verloren sind - es gibt keine neuen. Fir Benn ist der Nihilismus nicht zu überwinden, nur auszunützen. Es ist bei Benn das Leben, das man "fornend überwinden" soll, indem man die "formfordexnde Gewalt des Nichts" ausnitzt. Wo Nietzsche die Kunst als Verführerin zun Leben sieht, trennt Benn die Kunst vom Leben, wie wir im zweiten Teil dieser Arbeit sehen werden. 


\section{ZWEITER TEII}

VRRSUCH EINER NEUEN WERTSETZUNG 


\section{NIETZSCHES HETAPHYSIK DES WILLENS ZUR MACHT}

Zur Überwindung des allgemeinen Zerfalls der alten Werte schuf Nietzsche fine neue Wertsetzung und eine "Metaphysik". Dass es keine Metaphysik im christ]ich-platonischen Sinne des Wortes ist, haben wir im letzten Kapitel gesehen. Nietzsches Metaphysik des Willens zur Macht ist, wie die traditionelle Metaphysik, die Frage nach dem Seienden, nur liegt bei Nietzsche die Ant6ort auf diese Frage nicht ausserhalb, sondern innerhalb der Erfahrung. W Nari hat Nietzsche deri Philosophen des Werdens genannt, und nit Recht, (benn das Sein des Seienden ist fuix ihn ein Werden, ein Prozess. Das höchste Rinzip, das eigentlich Seiende, das primam mobile, nennt er den Willen zur Macht, und der Mensch (und alles Lebende) ist eire Form des Willens zur Macht. "Des Leben", heisst es j.m "Willen zur Macht", "als die uns bekannteste Form des Seins ist spezifisch ein Wille zur Akkumulation der Kraft." ${ }^{1}$ Hier wird gemeint, wir haben keine andere Vorstellung vom "Sein" als Leben, und das innerste Wesen dieses Seins ist Wille zur Macht. Darin erkennt Nietzsche den letzten Grund und Charakter aller Veränderungen und behauptet, es gibt keine physische, dynamische oder psychische Kraft ausserdem.

Um Missverständnissen vorzubeugen, muss gleich erwähnt werden, dass dieser wille nicht frei ist, wenigstens nicht im Sinne von dem "freien willen" der christlichen Tradition, denn er ist dazu bedingt, sich selbst zu wollen, das heisst, er strebt instinktiv nach immer mehr Hacht, nach einem Maximalgefühl von Macht.

Die alte Theorie von der Erhaltung des Lebens als allgemeines Handelns- 
prinzip wird mit der Lehre des Willens zur Macht widerlegt, denn aus Irfahrung wissen wir, dass der Mensch oft bereit ist, sich jeder Gefahr, auch der Todesgefahr auszusetzen, wenn es sich um ein Plus von Macht handelt, sei es Macht in der Form von Geld; Ansehen, Ruhm oder politische Macht. Die Lust-r Mntust Theorie des Handelns wird mit dem Prinzip des Willens zur Nacht auch widerlegt, und zwar aus dem selben Grunde wie die Theorie von der Erhaltung tes Lebens. Dasselbe gilt auch noch von der Theorie, dass Gluick das Ziel alles thandelns ist.

6. Über den krankhaften, unterdrickten Willen zur Macht haben wir bereits fanches erfahren. Die Skclaven, die Schwachen, die lissratenen und Schlecht-weggekommenen, die entweder vom Leben oder von anderen unterdrickt sind, die ifren Willen zur Macht nicht gelten lassen können, handeln auch rach dem WilIen zur Hacht, aber nach einem krankhaften Willen zur kacht, aus Ressentiment. Ir diesem Zusammenhang ist der Ursprung des Christentums ausgelegt worden. Ein weîteres Beispiel dafür wäre der Kranke, der seiner Macht so unsicher ist, dass er sie unbedingt zeigen muss, auch wenn dies daraus besteht, dass er andere zum Mitleiden expresst, dass ex ihnen das Leben schwer macht, indem or sie mit seinen eigenen Leiden belastet. Es gibt Leute, die nicht stark genug sind, allein zu leiden. Jede Handlung und jede Unterlassung hat also ihren Jrsprung in dem Willen zur Macht, sei diesex Wille normal oder krankhaft.

Der Wille zur Macht ist also für Nietzsche das Prinzip, worauf alles Geschehen beruht, die treibende Kraft. Damit wäre aber Nietzsches Metaphysik monistisch, denn sie würde alle Erscheinungen ouf e i a e Grundkraft zurïckführen. Wenn das der Fall wäre, wäre aber die İehre von der sublinierung des Willens zur Macht überhaupt nicht erk,lärbar, denn ein einziges Prinzip, wenn 
. es wirklich eine Einheit darstellt, kann schwer auf sich selbst wirken. Der Wille jst aber nur als Wort einfach. In Wirklichleit ist Wille ein vielschichtiges Phänomen und stellt eine Synthese des Apollinischen und des Dionysischen dar. Er könnte als ein dialektischer Monismus bezeichnet werden. Die Affekte, * die Triebe, die Vermunft und der Geist sind alle Äusserungen des Willens zur - Macht. Wille ist das Ergebnis der Koordination der Antriebe "unter der Vorherrschaft eines einzelnen." ${ }^{2}$ Wollen ist nie bloss Wollen, sondern ein "etwes 1. Wollen", und das Ziel des Willens, das wes gewollt wird, hängt davon ab, welcher Aritrieb die Vorherrschaft hat. Wer Wille ist nicht statisch, sondern dynamasch-schopferisch, und weist eine quast "unendziche Bewegung" auf, indem er ein Ziel entwirft, nach dessen Erreichung strebt, das erreichte Ziel übersteigt und wieder ein neues Ziel entwirft, erstrebt, erreicht und übersteigt. Von den Äusserungen des Willens, die miteinander um die Vorherrschaft wetteifern, ist die Ratio, die Vernunf, äie höchste. Der Wille ist weder identisch mit der Vernunft, noch steht er ihr feIndlich gegenüber, sondern wird durch die Vorherrschaft der Vernunft zur Ruhe und ins Gleichgewicht gebracht. Der schwache Mensch, den seine Trjebe und Affekte plagen, findet keine Ruhe: sein Wille ist in einem bitteren Kamp mit sich selbst. Nur wenn er seine Triebe unter der Vorherischaft der Vermunft sublimieren kann, wird ein Gleichgewicht erreicht.

Das Motiv der Selbstüberwindung, das in "Zarathustra" den Grundton anstimmt, erinnert dem Namen nach an die Selbstiberwindung und Askese der christlichen Religion. 3 Was Nietzsche amit aber verkünden will, unterscheidet sich, was den Grund und das Ziel der Selbstiberwindung betrifft, radikal vom Christentum. Der Christ soll seine Triebe und Leidenschaften ausrotten, weil sie 
schlecht und böse sind und weil er sonst nicht ins Himelreich kommt. Das Christentum ist in dieser Hinsicht negativ und baut auf Angst und auf ein schlechtes Gewissen. Wie wir aber gesehen heben, sind die Triebe und Affekte ir Nietzsches Augen keineswegs schlecht, sondern gegeben und nornal. Sie sollen keineswegs ausgerottet oder abgetötet werden, denn wer uber seine Triebe nicht herrschen kann und sie ausrotten muss, ist und bleibt schwach. Anstatt dessen 'sollen die Triebe sublimiert werden. Da es im Grunde nur eine Hrt Energie, nur eine Art Kraft gibt, kann man diese Energie unter des VorHerrschaft der Vernunftilenken und schöpferisch-positiv ausnützen. Die grossen Ginstier, zum Beispiel, hatten alle heftige Affekte und Triebe, Hätterr sie divese Triebe, hätten sie ihre libịdo durch Askese ausgerottet, so wären die sehönsten Gemälde und die schönste Musik nịcht entstanden, denn ex nilitio nithil fit. Die Triebe und Affekte sind ein wichtiger Bestandteil des Willens zur Macht.

- Der Wille offenbart sich in Handlungen und in Unterlassungen. Diejenigen, die schwach sind und aus Ressentiment handeln, und diejenigen, bei denen die Triebe die Vorherrschaft haben, sind nicht nur kleinlich und rachsiichtig in ihrem Handeln, sondern sie zeigen sich auch oft darin, dass sie es uberhaupt nötig haben, zu handeln. Ein Beispiel wäre wieder der Kranke, der seine Macht nicht anders zeigen kann; als dadurch, dass er andere in seine Leiden einbezieht. Da er seiner Mecht nicht sicher ist, findet er es rötig, sie zu zeigen, sich sèlbst und andere davon zu überzeugen. Ährlich is is es mit denjenigen, die eine Beleidigung oder eine Bemerkung nicht unterlassen kömen, und wit Frauen, die weinen, um etwas zu exreichen. Frreichen sie dann ihr ziel trotadem nicht, so haben sie mindestens den einen Trost, nämlich dass sie die Macht haben, den 
anderen die Iuaune zu verderben.

Diejenigen dagegen, und der J̈bermensch ist das beste Beispiel, die ihre Triebe sublimiert haben, die ihren Willen zur Macht ins Glejchgewicht gebracht haben, sind sich ihrer Macht wohl bewisst und finden es deshalb nicht nötig, sie immer durch Handeln zu zeigen. Das höchste Ideal ist, ein Meximum von Macht zu haben, unter anderem auch die Macht, anderen zu scheden, und von dieser Macht keịnen Gebrauch zu machen. Das ist der Übermensch, der auf einern *viel höheren Niveau steht als der Christ, der aus Argst oder um eirer Belohnsung willen handelt oder nicht handelt, auch wenn es in beiden Fällen un dieselbe Handlung oder Unterlassung geht. Solch ein Mensch ist es wert, "sinn der Frde" genannt zu werden.

Die Gestalten des Willens zur Macht sind, wie bereits erwähnt, Handlungen (oder auch Unterlassungen). Die höchste Gestalt, des Willens zur Macht ist die Kunst, die ejne zweifache quelle hat: sie stamit entweder aus Leiden und hat dann die Aufgabe, zum Weiterleben zu verfïhren, oder aber aus Freude am Leben, aus einem Maximalgefïh von Macht, und wirkt dann als ein Jubelruf, indem sie die Leberislust des Künstlers zurückspiegelt und das Dasein vergöttlicht. In diesem Zusammenhang ist der Satz aus dem Nechlasswerk "Die Unschuld des Werdens" zu deuten, der lautet: "Die Schöpfungen der Kunst sind das höchste Lustspiel. des Willens ..." 4 Kunst als eln Lustspiel, als ein Jubelruf des Willens gilt natürlich nur, wo es sich um das erhöhte Leben, den sublimierten Willen handelt. Bis dahin stammt die Kunst aus dem Leiden. Diese zwei Quellen der Kunst, die vom Zustand des Willeris determiniert werden, werden in den nächsten Kapiteln erörtert. An dieser Stelle sei nur noch kurz zusammengefasst, welche Folgerungen wir im Laufe unserer Untersuchung der Metephysik des Willens zur 
* Macht über die Kunst ziehen können: Kunst ist die höchste GestaIt des Willens zur Macht, Kunst ist eine Tätigkeit und Kunst ist nit dern Schaffenden - dem Küstler - im Hittelpunkt zu verstehen. 


\section{KUNST UND DAS ERHÖHTE LEBEN BEI NIETZSCHE}

Nietzsches neue Wertsetzung ist ein Bestreben, dem Menschen und dem

Leben eine neue Bedeutung zu geben. Dem verarmten Leben des Christentums, das den Körper und die Sinne als sündhaft wegleugnen will, setzt er seine Lehre des ganzen Menschen und der vollendeten Natur entgegen. Der Mensch ist eine Winheit von Körper" und Geist, whd der "Geist ist nur ein Mittel und Werkzeug 4him Bienst des höheren Lëbens, Ger Erhöhung des Lebens." ${ }^{1}$ Der Gipfel des er䊀öhten Lebens wird im Übermenschen erreicht, in dem Geist und Ieben, Geist und Körper, Vernunft und Triebe völlig und gliicklich vereinigt und irn GleichgeWicht sind, der seine Triebe sublimiert hat und schöpferisch ausnïtzt urd die "piriesterlichen und metaphysischen Verketzerungen der sinne" riicht mehr nötig

hât. 2 Er hat sich selbst uberwunden und hat den höchsten Grad von Macht erreicht: Macht über sich selbst. Illusionen hat er nicht mehr nötig. Nicht einem geheimnisvollen Wesen hinter den Wolken, der ihn belohnen oder bestrafen könnte, ist er verantwortlich, sondern nur sich selbst allein. Trotzdem handelt er gemäss seiner Würde. Er hat Würde, denn er hat sich zum Sinn der Erde hochgekämpft und ist nicht mehr ein armer sinder, ein Wurm. Er hat die Macht, Böses zu tun, tut es aber nicht, denn er hat es nicht nötig. Dieser schöne, utopische Traum von dem Übermenschen kann sich nie ganz verwirklichen. Trotzdem sòll man danach streben, denn dieses Ideal ist weder auf Angst noch auf Schwäche gegründet, sondern stellt eine höhere Schïtzung des Menschen dar als die des Christentums oder je einer anderen Wertsetzung.

Dass diese Lehre vom Übermenschen schon ofter missdeutet worden ist, ob 
mit"oder ohne Absicht, ist bekannt. Die Terminologie Nietzsches, und dariber wird später noch einiges gesagt, eignet sich besonders gut zu Vissdeutungen aller Art. So konnten die Nazis ihr Bild bei ihm bestellen, so hat ihn der George-Kreis missverstanden und so auch hat Benn den Übermenschen in einem biologistisch-darwinistischen Licht gesehen, und gegen Nietzsches "Zarathustra" als "Ziuchtungsoptimismus" polemisiert.

Zwischen den Jahren 1932 und 1950 erwähnt Benn Ni.etzsches Lehre von den (4) bermenschen in diesem Zusanmenhang nicht weniger als sechsmal. 3 In dem AufSatz aus dem Jahre 1932, "Nách dem Nihilismus", schreibt Benn:

(3. Es wird also doch der Übermensch sein, der den Nibilismus überwindet, 4. allerdings nicht der Typ, den Nietzsche ganz im Sinne seines 19. Jahrw hunderts schildert. Er schildert ihn als neuer, biologisch wertvolleren, als rassenmässig gesteigerten, vitalistisch stärkeren, ziuch* terisch kompletteren, durch Dauer und Arterhaltung gerechtfertigteren

Typ, er sieht ihn biologisch positiv, das war Darwinismus. 4

(*) Dass Nietzsche mit dem J̈bermenschen keineswegs eine biologistisch-darwinistische Lehre im Sinne von dem Menschen als ein hohes Tier und nichț weiter, vom Kampaf um das physische Dasein, von der Auslese der körperlich Starken und von dem Überleben der biologisch Tüchtigen verkünden wollte, zeigt sich schon in der Lehre von der Sublimierung der Triebe und in der von der Kunst als die höchste Gestalt des Willens zur Macht. Dass der Übernensch schon bei Nietzsches Irebenszeit solchen Missverständnissen ausgeliefert war, zeigt sich in diesem Satz aus "Ecce Homo":

Das Wort "Übermensch" zur Bezeichnung eines Typus höchster Wohlgeratenheit, im Gegensatz zu "modernen". Menschen, zu "guten" Menschen, zu Christen und anderen Nihilisten - ein Wort, das im Munde eines Zarathustra, des Vernichters der Noral, ein sehr nachdenkliches Wort wird ist fast überall mit voller Unschuld im Sinne derjenigen Werte verstanden worden, deren Gegensatz in der Figur Zarathustra zur Brscheinung gebracht worden ist: will sagen als "idealistischer" Typus eirier höheren Art Mensch, halb "Heiliger", halb "Genie" ... Andres gelehrtes Horm- 
. vieh hat mich sejnetwegen des Darwinismus verdächtigt ... 5

Nieht Naturalismus, sondern aie Vollendung der Natur ist der eigentliche Sinn

- der Lehre des Übermenschen. Ludwig Giesz warnt, dass der Übermensch "weder naturalistisch noch idealistisch" gedeutet verden soll. 6 Letzteres ist eine Gefahr, da der Übermensch faktisch unerreichbar ist, der dynamischen WerdensLehre. Nietzsches gemäss. Obwohl aber ein handgreifliches Übermensch-Sein weder gemeint noch möglich ist, ist der Weg zum Übermenschen dès Entscheidende; / und diejenigen, die sich zu "Vaterm und Vorfehren" des Übermenschen umtschaffen, nehmen schon an erhöhten Leben teil und werden dadurch "wahrhafte Wenschen", von denen es in der dritten dex "Unzeitgemässen Betrachtungen" heisst: "... wer sind die, welche uns erheben? Das sind jene wahrhaften Menschen, jene Nichtmehr-Tiere, die Philosophen, Kinstler und Heiligen." ? Damit sich der Mensch uberwinden und zum erhöhten Leben gelangen kann, muss sich die höchste Gestalt des Willens zur Hacht verwirklichen - die Kunst. Dex Mensch muss zugleich Schaffender - Kinstler - und Schöpfung - Kunstwerk sein. Hiermit haben wir einen wesentlichen Aspekt der Ästhetik Nietzsches berịhrt, nämlich seine Lehre von der Kunst im weiteren Sinne des Wortes.

Während für Benn, obwohl auch für ihn der Kínstler im Mittelpunkt steht, die Kunst immer den engeren Sinn von "Stein, Vers und Flötenlied" hat, also die bildende Kunst, die Dichtung und die Musik, versteht Nietzsche unter dem Begriff Kunst das Produkt des schöpferischen Gestaltens schlechthin, sei es im geistigen oder im physischen Bereich, sei es ein Gestalten von Kunstwerken aus einem Stoff oder ein Sich-selbst-Gestalten. In dem "Willen zur Macht" spricht Nietzsche von Kunstwerk "als Ireib, als Organisation (preussisches Offizierkorps, Jesuitenorden)" und von der Welt "als ein sich seibst gebären- 
des Kunstwerk". ${ }^{8}$ An einer anderen Stelle ist die Rede von der "Kunst in irgend welchen Formen, besonders als Religion und Wissenschaft". 9 Die Kunstperiode gilt für Nietzsche als "eine Fortsetzung der mythen- und religion-

" bildenden Periode. Es ist ein Quell, aus dem Kunst und Religion fliesst." 10

Um Missverständnissen vorzubeugen: Kunst bedeutet für Nietzsche keineswegs jedes "Machen", wie Heidegger in seinem Kommentar zu Aphorismus 796 des

"Willens zur Macht" onzudeuten scheint, indem er bemerkt:

4. Offensichtlich wird hier der Begriff der Kunst und des Kunstwerkese.

4. auf alles Hexvorbringenkönnen und jedes wesentliche Hervongebraehte.

* ausgeweitet. Das entspricht in gewisser Weise auch dem Sprachgebrarieh, 1. wie er bis an die Schwelle des 19. Jahrhunderts üblich ist. Bisidahin heisst Kunst jede Art von Hervorbringenkönnen. 1:II

dDass Heidegger die eigentliche Bedeutung der Kunst im weiteren Sinne bei Nietzsche nicht verkannt hat, wird in demselben Werk klar, wo Kunst "als Name für jede Form der verklärenden, bündigen Versetzung des Lebens in höhere Möglichkeiten" festgelegt wird. ${ }^{12}$ Bruno Hillebrand berihht dieselbe Deutung, indem er Kunst damit gleichsetzt, "was überhaupt Verklärang ermöglicht und damit das Leben wieder in seine innersten Rechte einzusetzen vermag, " 13 und deutet damit auf Heideggers "Gerechtigkeit" als Auslegung von Nietzsches Gebrauch des Wortes "Leben" hin.

Wesentlich für Nietzsches Auffassung von der Kunst ist also, dass die Kunst das Leben erhöhe und das Dasein verkläre. Damit berïhren wir zwei der von Benn so oft zitierten Nietzscheschen Kunstsätze, den von der Kunst als einer metaphysiscken Tätigkeit und den von der ästhetischen Rechtfertigung der Welt.

An mehreren Stellen der Werke "Der Wille zur Mecht" und "Die Ceburt der Tragödie" kehrt Nietzsches "Glaubensbekenntnis", sein "Artisten..Evangelium" 
wieder. ${ }^{14}$ Bereits im Jahre 1872, im "Vorwort an Richard Wagner", wird die *Kunst als "die eigentliche Aufgabe des Lebens", "als dessen metaphysische Tátigkeit" bezeichnet. ${ }^{15}$ In dem im Jahre 1886 geschriebenen "Versuch einer Selbstkritik" wird das Thema wieder aufgenomnen, diesmal mit einer parenthetischen Bemerkung über die Morel, indem Nietzsche "die Kunst - und nicht die Horal - als die eigentliche metaphysische Mäigkeit des Menschen" hinstellt." 7. Wir müssén hier im Auge behalten, dass "Leben" für Nietzsche "erhöhtes * tounkt seines Philosophierens und seiner neuen Wertsetzung steht und dass Wietzsche die Kunst als die höchste Gestalt des Willens zur Macht versteht, als das, was das Leben in höhere Möglichkeiten versetzt. Damit wird kIar, dass Nietzsche die Kunst als eine "diesseitsbezogene" Metaphysik, als Antipode zur lebensverneinenden, jenseitsbezogenen Metaphysik des Christentums ddchte, wie er seine neue Wertsetzung der Lebensbejahung und Vollendung der Natar als Antipode zum Christentum und zu dessen Verneinung dachte, die ja im Nihilismus geendet hat. In diesem Zusammenhang ist der Satz zu verstehen, dass ein Christ, der zugleich Künstler wäre, nicht vorkommt, 17 und die Behauptung, dass die Kunst "das Antichristliche, Antibuddhistische, Antinihilistische par excellence" ist. ${ }^{18}$ Es ist die Aufgabe des Willens, immer weiter zu wollen, immer mehr Macht zu wollen, eine imner höhere Art Macht zu wollen (die sublimierteste Macht als Macht über sich selbst). E's ist die Aufgabe des Lebens, sich selbst zu exhöhen, zu vollenden, was der bisherigen Metaphysik nicht gelungen ist. Der Versuch scheiterte; und das Ergebnis war der Nihilistous. Mit Nietzsches neuer Wertsetzung und Metaphysik der Kunst kann sich das Jeben erhöhen, deshalb wird die hunst die Aufgebe des Lebens, dessen meta- 
physische Tätigkeit genarnt.

Dass Benn diesen Satz Nietzsches in seinen Schriften neunral zitiert und variiert, ist bereits erwähnt worden. Allerdings ist Benns Variation für unsere Zwecke aufschlussreich, denn an zwei Stellen nennt er die Kunst "die letzte metaphysische Tätigkeit innerhalb des europäischen Nihilismus". ${ }^{19}$ An anderen Stellen heisst es, die Kunst sei die "einzige metaphysische Tätigkeit, zu der das Leben uns noch verpflichtet", 20 die "letzte Transzendenz innerHelto des grossen europäischen Wikhts:", 21 Die Terminologie, die Benn in diesen Tariationen benützt, zeigt, dess sie fiur ihn der Ausdruck einer existentiellen \& Auswegslosigkeit sind. Bass Wort "metaphysisch" scheint bei Bern eine ähnliche ? Quelle zu haben wie das wort "transzendent", das, wie wir gesehen haben, aus Bexns Auffassung van der Antinomie von Ieben und Geist, von Leben und Kunst stemmt. Da diese Antinomäe für Benn uniberbrückbar ist, gilt es nur noch, in Zuständen der Hyperämie das Irdische, das Leben zu ubersteigen. Fur Benn, für den alle traditionellen taphysischen Werte endgultig verloren sind und es keine neuen gibt, nimmt das Wort "metaphysisch" seine ursprungliche etymologische Bedeutung von meta physis", d.h. "höher als physisch", "ịber dem Physischen" an. Das ist das Geistige. Da aber der geistige Bereich versagt hat, da sich das logisch-diskursive Denken als nichtig erwiesen hat, gibt es nur noch e i n e geistige Aufgabe und Tätigkeit, nämlich den Ausdruck, die Form. Darin liegt einer der wesentlichen Unterschiede zwischen Benn und Nietzsche, nämlich dass für Nietzsche die Kunst dem Leben dient, indem sie es erhöht, wohingegen fiir Benn Kunst wnd Leben zwei getrennte Sphären sind und dje Kunst das Leben "formend überwinden" muss.

Nit dem Gedanken ton der Kunst als Aufgabe des Lebens und dessen meta- 
physischer lätigkeit eng verbunden ist der von der Rechtfertigurig der Welt als ästhetisches Phänamen. Dieser Satz wird ton Nietzsche öftex aufgegriffen und lautet an einer zentralen Stelle der "Geburt der Tragödie": "... nur als ästhetisches Phänomen ist das Dasein und die Welt ewig gerechtfertigt". 22 Obwohl wir die ästhetische Rechtfertigung der Welt noch im Zusammenhang mit Kunst als Sêönheitsschleier und als Verführerin zum Leben erörtern werden, kann dieser Gedanke an dieser Stelle als Ausdruck von Nietzsches Polemik gegen die tristlich-dogmatische Auffassung des. Daseirs und der Welt erwähnt werden. Dash Dasein und die Welt sind gegebene Phähomene. Lange sind sie von der christ 3 ch-platoni gehen Metaphysik verketzert worden, schienen aber als Vorstufe zxtm Jenseits und als Vorbereitung darauf gerechtfertigt. Es hat sich aber herausgestellt, dass das Jenseits eine Erfindung war, ein Versuch der Schwachen, dïe Starken zu schwächen und sie dadurch im Zaum zu halten. Dïe grösste Gefahr ist, nach Nietzsche, dass mit dem Verlust des Jenseits auch das Diesseits seinen Sinn verliert, und sein ganzes Philosophieren ist ein Versuch, das Diesseits als solches zu rechtfertigen, ohne sich auf ausserhalb der Erfahrung liegende, unbewiesene und unbeweisbare Prinzipien zu berufen. Wenn aber djese Welt und das Dasein nicht das Werk eines Gottes sind, kann es alles nur dann einen Sinn haben, wenn der Mensch, Kinstler und Kunstwerk zugleich, die höchste Gestalt seines Willens verwirklicht, die Lust an Schaffen, und sich selbst und die Welt erhöht und gestaltet. Dann ist die Welt, wie er selbst, sein eigenes Werk, und ihre Existenz, wie seine, gerechtfertigt. 


\section{KUNST UND WAHRHEIT BEI NIFTZSCEE}

Wir sind jetzt bereit, die Kunst in ihrer Funktion als Erlöserin und Verführerin zum Leben zu betrachten. Dje Kunst, die Religion und die Mythen haben nach Nietzsche eine gemeinsame Quelle - sie stamen alle aus dem Leiden am Dasein. Das Dasein mit den Schrecken der Natur und denen der WeItgeschichg te scheint, wenn durch kein grosses Cesetz gerechtfertigt, ephener, nicktig und sinnlos. In diesem Zusamenhang ist die Antwort des weisen Silen auf die Frage zu verstehen, was das Wünchenswerteste für den Menschen sei。 Des Satyrs Antwort war nämlich; das Beste wäre, niemals geboren zu sein, das Zweitbeste aber, bald aus dem Leben zu scheiden. Um das Leben erträglich zu machen braucht man Illusionen. Die Griechen schufen zu diesem Zweck Götter, die ihr Leben rechtfertigten, indem sie es selbst genau so lebten. Um das Leben und seine Schrecken ertragen zu können, stellten sie die glänzende Traungeburt der olympischen Welt vor die Schrecken des Daseins; wie einen Schönheitsschleier, der etwas Hässliches vexbirgt.

Das Christentum benutzt die "Wahrheit" als Illusion, verarmt dabei das Leben, ermöglicht es aber, indein es dem Leben die Funktion der Vorbereitung auf das Jenseits zuschreibt. Es soll in diesem Zusammenhang nicht verkannt werden, dass bei Nietzsche das Wort "Wahrheit" zwei völlig verschiedene Bedeutungen hat. Einmal hat das Wort die Bedeutung von Wahrhaftigkeit, wie zum Beispiel in "Ecce Homo", wo behauptet wird: "man verbot bisher grundsätzlich imner nur die Wahrheit". I Es ist die Wahrheit in diesem Sinne, von der Nietzsche sagt, der eigentliche Wertmesser für ihn sei, wieviel Wahrheit der 
Geist erträgt, Im Zusammenhang mit dem Christentum wird das Wort ironisch wand, und bedeutet, wie Heidegger meint, die "wahre Welt" im Sinne Platons und des Christentums, d.h., das Ujbernaturliche. ${ }^{2}$ Von dieser Art "Wahrheit" behauptet Nietzsche, sie sei "die Art von Irrtum, ohne welche ène bestimmte Axt son lebendigem Wesen nicht leben könnte." 3 Die Art von Wesen, die hier genneint wird, ist der schwache Mensch.

Wine höhere Illusionsstufe ist die der Wissenschaft, oder was Nietzsche Qte "sokratische Lust des Erkennens:" nennt, "wodurch man die ewige whide des Daseins heilen zu können wähnt". 4 Dem theoretischen Menschen ergeht es aber we dem religiösen, denn die Logik geht bis zu ihren Grenzen und beisst sich dann in den Schwanz. Dann bricht die tragische Erkerntnis durch.

Die höchste Illusionsstufe, der "Olymp des Scheins" oder Gipfel des Scheins, ist die der Kunst, ${ }^{5}$ denn, obwohl jede lllusionsstufe zum Giauben an das tieben verfuhrt, wird sie als einzige dem Leben und dem Menschen als harmonische Synthese von Körper und Geist gerecht.

"Ästhetik", heisst es in "Nietzsche contra Wagner", "ist ja nichts als eine angewandte Physiologie." 6 An anderen Stellen wird der "biologische Wert des Schönen" erwähnt, "7 und die Kunst "als organische Funktion" betrachtet. 8 Es geht Nietzsche Immer darum, das zu verkünden, was das Leben in "seine innersten Rechte" einsetzt, 9 was die Schrecker des Daseins weder wegleugnet noch mit erlogenen übernatürlichen Erklärungen zu rechtfertigen versucht, was das Gegebene (die Welt, den Körper und die Sinne) nicht als schlecht bezej.chnet und dabei das Leben verarmt, sondern anerkennt, schätzt und volIendet. Das ist die Kunst, die höchste Gestalt des Willens zur Macht, die es dem Menschen mögli.ch macht, die Schrecken des Daseins nieht nur zu ertragen, sondern auch 
zu bejahen, indem er erkennt, dass "im Schaffen ... das Zerstören eingerechnet" ist. 10

Der Wille zur Macht, den wir schon als die bewegende Kraft, das primum mobile des Handelns bezeichnet haben, besteht aus zwei Elementen, die die fortwährende Bewegung des Willens ermöglichen, nämlich aus dem Dionysischen und dem Apollinischen. Diese äussern sich im physiologischen Bereich als Traum und Rausch, und aus diesen zwei physiologischen Zuständen entsteht die Kunst. Dionysisch ist das Chaotische, das Abgrüidige, das Zerstörerische und der Ursehmerz am Dasein. Apollinisch hingegen ist die Verklärung, der Schein, die Form, die Ruhe und die Oberfläche. Für die Entstehung der Kunst sind beide Elemente notwendig; und verhalten sich in direkter Proportion zueinander. Je grösser, je tiefer das Leiden, desto grösser die Not und der Antrieb zur ErIösung, zum Schein. Das Dionysische ohne die apollinische Verklärung führt zum Chaos und zum Untergang, ist aber die conditio sine qua non für die Entstehung der Kunst, wenn das Apollinische hinzukommt. Von dem Rauschhaften als Vorbedingung für Kunst heisst es in der "Götzen-Dämmerung":

Damit es Kunst gibt, damit es irgend ein ästhetisches Tun und Schauen gibt, dazu ist eine physiologische Vorbedingung unumgänglich: dex Rausch. Der Rausch muss erst die Erregbarkeit der ganzen Maschine gesteigert haben: eher kommt es zu keiner Kunst. Alle noch so verschieden bedingten Arten des Rausches haben dazu die Kraft ... Das Wesentliche am Rausch ist das Gefuhl der Kraftsteigerung und Fillle. II

Einige der verschieden bedingten Arten des Rausches, von denen hier die Rede ist, sind der Geschlechtstrieb und die Grausamkeit, die "zur ältesten Festrreude des Menschen" gehören. "12 Es ist eine Mischung von Begierden und Wohlgefühlen, workus Energie und ein Verlangen nach Verklärnng entstehen, die in den ästhetisehen, d.h. schöpferischen Zustand versetzen, Dieser Zustand des 
- Bewegtseins, der Begierde und des Verlangens nach Überwindung, wirkt als Stimulans, als Wille zur Form, zum Schein, zur Oberfläche, kurz zum Apollinischen, ohne das es zum Chaos fuhrte. Das Negative zieht das Positive an, das Chaos den "Kosmos", das Abgriindige das Oberflächliche wie ein Magnet, so elementar ist der Weltwille zur Macht, zur Erlösung und zur Steigerung der Macht. Das Produkt, das Kunstwerk in engeren oder im weiteren Sinne des Wortes, wirkt dann wiederum als Stimulans zum Schaffen, indem es den Zustand des schaffenden Kunstlers mitteilt und damit von neuem erregt. Kunst wirkt als Stimulans zur Kunst, indem sie tonisch wirkt. Sie

mehrt die Kraft, entwindet die Lust (d.h. das Gefuhl der Kraft), regt alle die feineren Erinnerungen des Rausches an, - es gibt ein eigenes Gedächtnis, dàs in solche Zustände hinunterkomint: eine ferne und fliichtige Welt von Sensationen kehrt da zurück. 13

Die Kunst ist der 01ymp des Scheins, die höchste Illusionsstufe und die einzige, die der Wirde des Menschen entspricht, denn im Kunstprozess wird das Dionysische nicht ausgerottet oder weggeleugnet, sonderm sublimiert und schöpferisch ausgenützt, und es erlöst und verfuhrt dadurch zum Leben. Kunst ist die Auṣniatzung des Hässlichen zur Frschaffung des Schönen. Kunst wirkt als "Heilmittel der Erkenntnis". ${ }^{14}$ Wer die Schrecken des Daseins sieht und nicht wegleugnet, braucht die Kunst als Erlösung. "Die Wahrheit ist hässlich", gesteht Nietzsche ein, "wir haben die Kunst, damit wir an der Wahrheit nicht zugrunde gehen." ${ }^{15}$ Je tiefer die Erkenntnis, desto notwendiger ist die Kunst. Die Griechen, die die Schrecken der Natur und der Weltgeschichte erkannten, waren in der Gefahr, den Willen buddhistisch zu verneinen. Sie brauchten deswegen den metaphysischen Trost der Kunst, insbesondere die der Tragödie. Durch die Kunst der Tragödie wird der Zuschauer eins mit dem Weltwillen, dem Finen 
Lebendigen. Der Held wird zu des Zuschauers Lust verneint, weil er doch nur "Erscheinung ist und das ewige Leben des Willens durch seine Vernichtung nicht berüht wird." ${ }^{16}$ Dadurch wird dem Zuschauer beigebracht, dass im Schaffen das Zerstören eingerechnet ist, dass das Zerstören das Schaffen erst möglich macht. Der Zuschauer wird von der Urlust am Dasein überzeugt, indem er von seinem eigenen Willen momentan erlöst wird, mit dern Weltwillen verschmilzt und die Iust des Daseins nicht in den Erscheinungen sucht, sonderm hinter den Erscheinungevif und "unter dem unaufhörlichen Wechsel der Erscheinungen die ewig schöpferissche, ewìg zum Dasein zwingende" Natur erkennt. ${ }^{17}$ Die Kunst ist eine Nachahoung der. Natux, indem sie żum Leben verfihrt.

Der Kunstsatz Nietzsches von der ewigen Rechtfertigung der Welt und des Daseins nur als ästhetisches Phänomen bedarf an dieser Stelle einiger Bemerkungen im Zusammenhang mit dem Thema Kunst und Physiologie. In der "GötzenDämmerung" heisst es:

Physiologisch nachgerechnet, schwächt und betrübt alles Hässliche den Menschen. Es erinnert ihn an Verfall, Gefahr, Ohnmacht; er büsst tatsächlich dabei Kraft ein. Man kann die Wirkung des Hässlichen mit dem Dynamometer messen. Wo der Mensch überhaupt niedergedriickt wird, da wittert er die Nähe von etwas "Hässlichem". Sein Gefühl der Macht, sein Wille zur Macht, sein Mut, sein Stolz - das fällt mit dem Hásslichen, das steigt mit dem Schönen. 18

Das Christentum hatte das Leben verarmt und den Menschen geschwächt zugunsten des Jenseits, das es aber gar nicht gibt. Die Schrecken des Daseins und das Hïssliche sind aber gegeben, und könnten den Menschen derart verarmen und schwächen, dass er seinen willen zum Weiterleben verliert und zugrunde geht. Wenn man aber die Welt und das Dasein als Äusserungen des Weltwillens betrachtet, das Zer'stören als im Schaffen eingerechret und das Hässliche a]s Antrieb zun künstlerischeri Schaffen und als dessen conditio sine qua non, dann 
hat auch das Hässliche einen Sinn. Wenn aber das Hässliche einen Sinn hat, wenn es zum Schaffen des Schönen notwendig ist und das Schöne zum Weiterleben v'erführt, indem es den Menschen tärkt und erhebt, dann ist nicht nur das Hässliche, sondern auch die Welt, in der es existiert, gerechtfertigt. Das Hässliche wird dann als Katalysator gesehen, ohne den das Leben in seine innersten Rechte nicht eingesetzt werden könnte. Der Wert für das Leben ist das Entscheidende bei Nietzsche, der die Kunst unter der Optik des Lebens sieht. Die Welt als ästhetisches Phänomen verfuhrt zum Leben. 
BEINN UND IIE NONOLOGISCH-PONOMANE KUNST

Wie wir im ersten Teil dieser Arbeit gesehen haben, sind Geist und

Leben fïr Benn zwei endgültig getrennte Sphären. Die von der zivilisatorischen Menschbeit geschaffene "Wirklichkeit" hat einen endgïltigen Zusammenbruch erFitten und es bleiben nur noch die Bruchstiucke. "Zerfetzt der innere Mensch, zerfetzter als je der äussere von Wirmern und Granaten: ... die Götter tot, aie Kreuz- und Weingötter, mehr als tot ..." ${ }^{l}$ Alles ist ins Schwanken geI raten. Mit der Trennung von Geist und Lebein (Wirklichkeit) muss es auch eine Antinomie von Kunst und Leben geben, denn Kunst ist das Produkt des Geistes. Da das, was bjsher "Wahrheit" hiess, fragwürdig geworden ist, haben Kunst und. Wahrheit fur Benn nichts miteinander zu tun. Der Denker kann sich nicht mehr in den bisherigen logischen und kausalen Kategorien mitteilen, da sie für ihn verloren sind. Das Logisch-Diskursive hat versagt und den Geist in dje Isolierung gedrängt.

Der Geist kann sich nux noch im Schaffen mitteilen, aber auch damit ist es fragwiirdig geworden. Die Werte und Ideen, denen die bisherige Kunst gedient hat, gelten nicht mehr, und die Worter haben ihren Inhalt verloren. Die Werte ausserhalb des Ich haben sich dexartig relativiert, dass sie riicht mehr als Maßstäbe dienen können. Es gibt keine höheren Zwecke, denen die Kunst unterstellt ist: sie hat nur noch sich selbst als Ziel und als Maßstab. Benn, der Kunst in einem engeren sinne als Nietzsche versteht, meint darunter hinterlassungsfähige Gebilde, "Stein, Vers, Flötenlied ... abschliessbare und abgeschlossene Gebilde: Kunst - diese sagt nux sich selbst, ist ohne Idee und ist 
"vollendet." ${ }^{2}$ Die Kunst hat keine geschichtlichen Ansatzkräfte: denn was bedeutet noch die Geschichte? Sie will weder besserr (wie denn?) noch belehren (was für Lehren gibt es noch?). Sie soll niemanden ansprechen (wer hörte noch zu?) und hat keine Aufgabe. Die Kunst, von Benn meistens im engsten Sirrie von Dichtung besprochen, wird solipsistisch: "Ein Gedicht ist immer die Frage I nach Gem Ich, und alle Sphinxe und Bilder von Sais mischen sich in die AntJwort ein." 3 Die Kunst, die Dichtung, ist also monologisch-monoman und an 1 niemanden gerichtet. ${ }^{4}$ Benn nennt die Lyrik eine "anachoretische Kanst"n 5 und yeint, der Kunstler muss das Ieben ausschliessen und bekämpfen, um es zu. stiHisieren. Der Kiunstler kann keinen Nebengedanken, keinen höheren Sinn mit der Dichtung verbinden - nicht ejnmal die menschiliche Sphäre zähit dazu.

Da die. Inhalte verloren sind oder sich relativiext haben, hat das mo-derne Gedicht eigentlich keinen Inhalt jm traditionellen Sinne des Wortes. Es kann nicht mehr auf den Inhalt ankommen, nur noch auf die Form, die selbst zum Inhalt wird. "Die Form" wird für Benn "die absolute Kunst". " Die Bedeutung, die Benn der Form beimisst wird verständlich, wenn man bedenkt, dass der abendländische Mensch geistig-inhaltlich das Stadiun eirer ausgequetschten Zahnpastatube erreicht hat, dass ihn nichts mehr trägt und dass er Gefahr läuft, an dem Nichts zugrunde zu gehen. Die Form kann Ordnung, wenn auch keinen Inhalt, in das Chaos bringen und nur durch die Form, durch "Stein, Vers, Flötenlied" kann der Mensch etwas von sich selbst vor dem allgeneinen Untergang und der Zerstörung retten, und sich eine quasi Dauer verleihen. In diesem Sinne ist der Satz aus dem Essay "Dorische Welt" zu verstehen, der lautet: "Die Kunst ist mehr als die Natur, und der Läufer (Statue) ist weniger ds das Leben', das heisst, alles Leben will mehr als Leben, will Umriss, 
Stil, Abstraktion, vertiertes Leben, Geist." 7 Weil a]les ephemer ist, weil alles dem Verfall geweiht Ist, ist die Schöpfung "das Verlangen nach Form" und der Mensch "der Schrei nach Ausdruck". 8

Benns Ansicht nach kommt es nicht darauf an, ob man Nihilist ist oder nicht, sondern was man aus seinem Nihilismus macht. Fur Benn kann der Nihil4ismus schöpferisch ausgerützt werden, denn das Nichts hat eine "formfordernde Gewalt", 9 Solange es noch Inhalte gab, auf die man sich berufen konnte, gab Fes keine Kunst an sich. In dieser Beziehung nennt Benn Gott ein schlechtes Stilprinzip, denn "wenn religiös wird, erweicht der Ausdruck." 10 In der 1 Kunst geht es für Benn mixht um die Wahrheit, sondern um Expression, und die teinzige Ethik, die er für den Künstler noch anerkennt, ist die der eigenen Wollendung durch Ausdruck und das Erkämpfen der Form sozusagen ex nihilo. Diese Vollendung des Künstlers ist die Monomanie der Bennschen Âsthetik - der einzige Gedanke, der mit der Kunst noch verbunden werden kann. Insofern das Nichts den Küntler dazu zwingt, sich selbst durch das Scharfen zu vollenden, ist "Nihilismus ... ein Gläcksgefïhl." 11

Der Nihilismus macht die Kunst notwendig und-seine Gewalt wird zum Antrieb gur Produktivität und spornt den Künstler an, "das Leben formend [zu] überwinden." 12 Die formende Uberwindung des Lebens, dessen, was "Wirklichkei.t" genannt wird, hat eine zweifache Bedeutung bei Benn. Einmal weist diese Formel. auf die bereits erwähnte "Transzendenz der schöpferischen Iust" hin, ${ }^{13}$ wobei freilich kein übernaturluches Prinzip gemeint wird, vielmehr ein Übersteigen der fragwirdig gewordenen "Wirklichkeit", ein Dariberhinwegsehen und -gehen, wodurch die Kunst von der "Uirklichkeit" isoliert wird und als absolut, als $I^{\prime}$ art pour I'art ihre Eigengesetzlichkeit gewinnt. Da die Kunst keinen höheren 
Ideen dienen solI noch kenn, wird das Hittel zun Zweok gemacht, die Inhalte durch die Form ersetzt. Die zweite. Bedeutung der Formel von der formenden

t Uberwindung des Lebens weist auf den schöperischen Prozess hin, auf die hyperämische Metaphysik, wodurch der Kinstler die Wirklichkeit zertrimnert und mittels der hyperänischen Zustinde zur Vermischung mit der Ureinen gelakgt - ein Zustand des Vergessens, in dem er Formen schafft und von dem es Afm Gedicht "Nacht" heisst: "Ach! Äonenvergessen!/ Schlaf! aus mohnigem Feld,/ Fivis dem lethischen Essen/ zieht ein Atem der Welt,/ von acherontischen Zonen/ prphisch apotheos/ rauscht die Hyme der Drohnen:/ Glicke des Namertom, 14 7. Etr Benn wird der Formalisms zu einer neuen Ritualitit: die absolute funst der Form ist keineswegs das, "was das burgerliche Deutschland ... bis heute verächtlich "Artistik' nennt .... sondern .... tief, religtös und sakramental". 15 obwohl aber die form fur Benn ein "fast religiöser Versuch" ist, "die Kunst aus dem Asthetischen zum Anthropologischen zu uberfihren", 16 das heisst, der Menschheit ein neues Absolutes zu geben, das sie trägt, kormat ex un die Tatsache nicht herum, dass, diese absolute Kunst der Form im Grunde eine Flucht ist, "ein Schritt aus Fluchtingselend zu einen Studdengott, 17 und dass die "Tiefo" der "Oberflächlichkeit aus Tiefe" der Abgrund, das Wichts ist und bleibt. Dass Benn sich dieser Tatsache bewuast war, beweist or in der "Akademie-Rede":

Aber wir kogamen un die Frage nicht herum, was erleben wir denn nun in diesen Räuschen, was erhebt sich den in dieser schöpferischen Lust, was gesteltet sich in ihrer Stunde, was erblickt sie, auf welche Sphinx blickt dean ihr exweitertes Gesicht? Und die Antwort kann nicht ander's lauten, sie erblickt auch hiex am Grunde nur ströraendes hin und her, eire Ambivalenz zwischen Bilden und Entformen, Stundengotter, die auflösen und gestalten, sie erbllakt etwas Biindes, die Natur, exblickt das Nehts. 18 
Am Anfang steht also der Schmexz des tragischen Ich, des entwurzelten Ich, über den es keinen Sieg gibt. Fir Augenblicke aber kann es die Wirklichkeit, die es umgibt und isoliert, durchstossen und zertrimmern und mit dem Unendlichen, das das Schöpferische birgt, dem Urgesicht verbunden" gein, 19 und geine Existenz in Formen bestätigen, bevor es dann wieder in dje kalte, amorphe wirklichkeit zuricksinkt. 


\section{BENTIS ADSDRUCKSWELT}

Benn nennt seine Kunsttheorie "Expressionismus", oder noch lieber "Aushackswelt". Dieser Begriff weist darauf hin, dass es nach dem Inhaltsverrust nur noch das Ich gibt, das sich durch einen nach aussen gelagerten Stil * formend kundgibt. Der expressionistische stil schildert nicht, ex ist das ischöpferische Agens an sich. Die Sprache will und kann nichts als "phosphóreszieren; luziferieren, hinreissen, betäuben". 1 Ais die Sprache noch eine Wirklichkeit schilderte, war jedes Wort wichtig. Mit dem Wirklichkeitsqusamanenbruch aber haben Adjektive und Zeitwôrter ihre Bedeutung verloren, oder wite es in dem Gedicht "Schädelstätten" heisst: "Schädelstätten,/ Begriffsmanie,/ kein Zeitwort zu retten/ noch Historie $-^{n} .^{2}$ Der Romancier beschrieb mit dem Wort, er brauchte Stoffe und Themen. Der Expressionist hingegen deutet mit dem Wort an; er fuhrt kein geschlossenes Thema vor und es gibt oft keine inhaltliche Beziehung zwischen den einzelnen Versen, nur noch eine suggestive und ausdruckshafte.

Benn stellt sich den Dichter yor als über dem ganzen Organismus mit Fimmerhaaren bedeckt, deren Reizbemerkung den assoziativen Wortex gjlt, besonders den Substantiven, die der Dicllter aus schöpferischer Spannung ergreift. Diese Worte haben eine positive Funktion jenseits des Begrifflichen, Erzählenden und Beschreiberiden. Sie haben die Macht der Suggestion. In dem Aufsatz "Schöpferische Konfession" begründet Benn seine Neigung zum assoziativen Wort:

Wi oh sensationiert eben das Wort ohne jede liigksicht auf seinen be- 
schreibenden Charakter rein als assoziatives Motiv urid dann empfinde ich ganz gegensätzlich seine Eigenschaft des logischen Begriffs als den Querschnitt durch kondensierte Katastrophen. Und da ich nie Personen sehe, sondern immer nur das Ich, und nie Geschehnisse, sondern immer nur das Dasein, da ich keine Kunst kenne und keinen Glauben, keine Wissenschaft und keine Mythe, sondern immer nur die Bewusstheit, ewig sinnlos, ewig qualbestuirzt-, so ist es jm Grunde diese, gegen die ich mich wehre, mit der sülichen Zermalmung, und sie, die ich abzuleiten trachte in ligurische Komplexe bis zux Überhöhung oder bis zum Verlöschen im Aussersich des Rausches oder des Vergehens. 3

In der Erzählung "Der Geburtstag" macht der Arzt Rönne die Beobachtung, dass A sich manche Worte besonders gut dazu eignen, Assoziationen auszulösen, die ci: den Stiden betreffen. Benn nennt diese Worte "ligurische" odex "suidliche Kom(plexe", Worte, die besonders dazu geeignet sind, die Sidjichkeiten und die Mhyperämi schen Zustände heraufzubeschwören. Es sind Worte mit Rauschwert, mit Hallungswert". "Blau" ist das Sidwort schlechthin: "Sphinxblau" und "frevelhaftes Blau". Es sind Worte wie "Anemonenwälder", "Narzissenwiesen", Marmorstufe", "Phäaken" und "Megalithen"; Botanisches, Geographisches und Historisches. Die meisten sind Substantive, Namen, aber wenn man sie heraufbeschwört werden sie mehr, denn sie öffnen die Schleusen, vollziehen die "Zusammethangsdurchstossung" und führen die Vermischung herbei. So ist Benns Bemerkung über Rönne als "eine Illevation durch das Wort, eine Sakramentation des Wortes, ein Heiligungs- und Erlösungsphänomen mit Hilfe des dichterischen Wortes" zu verstehen. 4

Die Grundlage für Benns Theorie der Kunst als "Ausdruckswelt" ist mit einer Art Solipsismus eng verburden, denn als Wirklichkeit im eigentlichen Sinne gilt für ihn nur noch das, was in Innern ist. Wie ex dieser lage bemusst wurde schildert Benn in dem Essay "Epilog und Iyrisches Ich" folgender. massen: 
Ich vertiefte mich in die Schilderungen des Zustandes, der als Depersonalisation oder als Entfremdung der Wahmehmungswelt bezeichnet wird, ich begann, das Ich zu erkennen als ein Gebilde, das mit einer Gewalt, gegen die die Schwerkraft der Hauch einer Schneeflocke war, zu einem Zustande strebte, in dem nichts mehr von dem, was die moderne Kultur als Geistesgabe bezeichnet, eine Rolle spielte, son-

f dem in dem alles, was die Zivilisation unter Fihrung der Schul- inedizin anrïchig gemacht hatte als Nervenschwäche, Ernidbarkeit,

to Psychasthenie, die tiefe, schrankenlose, mythenal te Fremdheit zut. gab zwischen dem Menschen und der Welt. 5

- Der'innere Mensch ist also der Ausgangspunkt und der Ausdruck das EntSheidende. Da aber der innere Mensch in Isolierung und Erstarrung lebt, muss 4. mit Hilfe der Worte nit Wallungswert die Ratio lockern. Er muss hinüber\%hen "aus starre und Gebnandenheit in Strömen und Vergehen. " 6 Der Phänøtyp d 20. Jahrhunderts trägt also die Zuige eines Narziss.

Es ist merkwïrig and aufschlussreich im Zusammenhang mit den hyperämitschen Reichen, die zux Zusamenhangsdurchstossung und zum Einssein mit dem Urgesicht führen, wie oft das Vokabular Benns in dieser Beziehung einen Zustand des Vergessens schildert oder wenigstens andeutet, oder den Tod als endgültiges Vergessen. Besonders in den Gedichten, aber euch in der Prosa, häufen sich Ausdricke, die das aufgelöste Bewusstșein andeutet, wie "somambul", "doldenverrauscht", "trunkene Flut" die die Seele deckt", "Ich-Zerfall", "Schlaf aus mohnigem Feld", "Äonenvergessen", "orphisch", "lethisch", "die acherontischen Zonen" und "Raumverdrang". In dem Gedicht "Untergrundbahn" heisst es: "Fernes Glück: ein Sterben/ hin in des Meeres erlösend tiefes Blau". 'Auf das quasi-sterben, das in dem Zustande der Vermischung mit dem Urgesicht stattfindet, wind mit den Wörterm "Schatten", "Nacht", "Asphodelen" und "stygische Elut" hingedeutet. Der Zustand der sinsfühlung des Ich mit dem Urgesicht bedeutet also die Ureisgabe der Eigenpersönlichkeit und des Bewrusst- 
seins. Das ist ein Untergang, aber es ist auch eine Befrejung von der Starre und öde der "Wirklichkeit", eine Entspannung der Ratio und eine Erlösung von dem schmerz an Dasein. Deshalb ist dieser Vorgang, der ja in Grunde ein kathartischer ist, auch eine Auferstehung. Hs ist der Weg aus der Bewusstheit durch das Unbewusste in die Kunst: das narzisstische Ich geht unter und das schöpferische Ich steht auf. Dieses schöpferische Ich, durch den Schmerz in den Zustand der Vermischung getrieben, gevinnt die Kraft, seinen Schmerz abat

utuilden und sich im Formen Runstlerisch davon zu erlösen. Es ist diese ErT.

sung, die Benn im "Lebensweg eines Intellektualisten" meint:

1.

Genug der Wahrheit. Formales möge kommen ... Oberflächen-: Stil-! ...

W. In diesem grund]egenden Gefuhl für die anthropologische irlösung im

* Fornalen, für die Reinigurg des Iraischen in Begriff beginnt die neue

- Fpoche, das neue Notwendige.... die Form- und ...Ausdruckswelt. 8 
DRITTER TIEIL

ZUSAMMENTASSUNG DER KUNSTTHEORETISCHEN PERSPEKTIVEN 
RESIGNATION UND AMOR FATI

Wir sind jetzt bereit, das Fazit zu ziehen und, nachdem wir die Einstellungen Benns und Nietzsches zu der allgemeinen Grundlagenkrise zusammengefast haben, die Unterschiede in der Kunsttheorie der beiden, die aus ihren Binstellungen notwendig folgen, näher ins Auge zu fassen. Hier kommt der Unterchied zwischen dem Känstier Bern und Notzsche, der in erster Iinie Philosugh war, deutlich zum Vorschein. Wie im Vorwort angedeutet wurde, sieht Benk sein Vorbild in Sachen der Kunst als Zerstöres und Nihilisten. In dem -aus 得en Jạre 1950 stammenden Essay "Nietzsche - nach funfaig Jahren" heisst es, Nietzsche sei ${ }^{\circ}$ der vierte Mensch", von dem man jetzt so viel spricht, der Mensch ohne Inhalt". In demselben Essay und in einem zwei Jahre später geschriebenen Brief an Alexander Lernet-Holenia meint Benn, Nietzsche habe die Inhalte selbst zerstört, nur un die "Bruchflächen funkeln zu lassen ... ohne Büicksicht auf die Brgebnisse". 2 Benns Ansicht nach hatte Nietzsche "alles zerbrochen, was inm begegnete: Philosophie, Philologie; Theologie, Biologie, Kausalität, Politik, Erotik, Wahrheit, Schlüsseziehen, Sein, Identität ..." 3 An zwei verschiedenen Stellen neint Benn, dass von allen grossen Minnern der weissen Rasse, die seit Jahrhunderten nur die eine innere Aufgabe empfunden hätten, nämlich ihren Nihilismus zu verbergen, habe sich Nietzsche am längsten naiv gezeigt. 4

Dass das Epitheton "Nihilist" in Fall Nietzsches keineswegs verwandt. werden kann, geht von seiner neven Wertsetzung hervor. Wenn Nietzsche, wie er im Untertitel zur "Götzen-Dänmerung" behauptet, "mit dem Hammer philosophiert", 
so bedeutet das keineswegs, dass er unbedingt alle Werte zerstören will, Vielneh dass er die Ruinen der sogenannten "wahren Welt" im Simne der christlich-platonischen Metaphysik, die den Keim des Untergangs vom Anfang an in sich getragen hatte, endiich und endgültig wegräumen will. ${ }^{5}$ Dazu tut aber. Wahrhaftigkeit not, denn man muss aufhören, sich selbst über den Ursprung, das Ziel und die Wahrheit der traditionellen "Metaphysik" zu belïgen. Hur wenn das, was die Menschheit bis jetzt geschwächt und damit in Zaum gehalten hatte, vernichtet vird, kann die neue Wertsetzung Fuss fassen. f Benn hat offensichtlich nur die erste Phase der philosophischen Bemiihungen Nietzsches, die Phase der Zerstörung der Reste der alten Werte, erkannt. i:

Bei Nietzsche ist diese Phase aber nur eine notwendige Vorstufe zum eigentlichen Ziel - zur neuen Wertsetzung, zum Schaffen der neuen, diesseitsbezogenen Werte. Um schaffen zu können, muss man aber hart sein, heisst es in "Zarathustra", 6 man muss zerstören, was im Wege steht und sowieso falsch ist. Es ist wichtig im Auge zu behalten, dass, wie bereits erwěhnt, Nietzsche die décadence (d.h. die alten höchsten Werte der christlich-platonischen Metaphysik) mit dem Nihilismus gleichsetzt, denn sie sind es, die als falsch und unnatïlich die Ursache ihrer eigenen Entwertung sind. Sie sind mit dem Nihillismus kausal verbunden - sie mussten notwendig in den Nihilisimus minden. In diesen Zusammenhang redet Nietzsche von "Christen und anderen Nihilisten", denn Christ sein heisst für ihn, die unausweichliche Folge des Christentums und des Christseins, den Hihilismus, in sich tragen. "Alles, was in der Schwäche getan wird, missrät", 7 und dass das Christentum eine Religion der Schwäche ist, haben wir bereits gesagt. Das Christentum, als Verneinurg des diesseitigen Lebens, wird im "Antjchrist" "der Wille zun Ende, der nihilist- 
ische Wille zur Macht" genannt. 8

Es ist also klar, dass Nietzsche, seiner eigenen Definition des Wortes nach, kein Nihilist ist. Im "willen zur Macht" definiert Nietzsche den Begaiff "Kihilismus" folgendermassen: Was bedeutet Nihilismus?- Dass die oberoten Werte sich entwerten. Es fehlt das Ziel; es fehlt die Antwort auf das Marum" ". 9 Dass sich die obersten Werte entwertet hatten, wurde von Nietzsche zur Kenntnis genormen. Er schuf aber neue Werte und gab der Menschheit ein aeues Ziel, das erhöhte Leben, womit er dem diesseitigen Leben gerecht wurde, nab dabei eine neue Antwort auf das "Warum?". Nietzsche war der erste, der Gine Einsicht in die Lage hatte, die der Menschheit zum Verhängnis murde - die décadence - und der erste, der das Leben zu retten beniht war, indem er der Manschheit eine neue Anschauung gab, die das Zerstören als einen notwendigen Teil des Schaffens anerkannte, ohne sich auf eine überirdische Phantasiewelt berufen zu müssen. Diese Anschaung schliesst das Zerstören und auch das Leiden als notwendig ein, denn durch Leiden wird man stärker und lebenstivchtiger. Diese neue Weltbetrachtung, die wirklich eine Weltbetrachtung und keine Hinterwel tbetrachtung ist, lehrt, das Ganze zu bejahen - sie lehrt amor fati.

Wie steht es mit Benn in Bezug auf die Grundlagenkrise, die zum Nilails ișmus gefuhrt hat? Dass für Berm die wirklichkeit", die die zivilisatorische Menschheit nach dem Verlust der prälogischen Geistesart und mit der progressiven Zerebration schuf; sich endgultig entwertet und entwirklicht hat, steht, ausser Zweifel. Wir haben es im ersten Teil dieser Arbeit erörtert. Dass es flir Benn keine neuen Werte gibt, ja dass für ihn selbst die Kunst eine Art lethische Flucht vor dieser Lage ist, dass man in den hyperämischen Zuständen das Nichts erblickt, gesteht Benn selbst ein. Seine "Transzendenz der schöp- 
ferischen Iust", seine formende Überwindung des Lebens, seine Isolierung der Kunst vom Leben, von der Wirklichkeit - all das sind Versuche, fur einige Zejt das auszuschalten, woran die Erinnerung weh tut. Jiese Erinnerung tut Benn weh, wejl er im Grunde über den Verlust der Wirklichkeit trauert:

Wirklichkeit-, Europas dämonischer Begriff: glücklich nur jene Zeitalter und Generationen, in denen es eine unbezweifelbare gab, welches t. tiefe erste Zittern des Mittelalters bei der Auflösung der reliciösen, $\therefore$ welche fundamentale Erschütterung jetzt seit 1900 bei Zertrummerung f der naturwissenschaftlichen, der seit vierhundert Jahren "wirklich" gemachten . $\therefore 10$

3. Benn bekennt sich ganz offen zum Nihilismus als "eine innere Realitä... Whilismus als Verneinung von Geschichte, Wirklichkeit, Lebensbejahung ist (t)

ine grosse Qualität; als Realitätsleugnung schlechthin bedeutet er eine Verringerung des Ich." II $\mathrm{Er}$ weist aber darauf hin, dass ein modernex Mensch nicht nihilistisch (d.h. negativ) denkt, sonderm sich eine Grundlage für seine bxistenz schaff, die fir viele auf Resignation beruht: "Resignation fürt [die] Perspektiven bis an den Rand des Dunkels, aber sie bewahrt Haitung auch vor diesem Dunkel." 12 Benn, fïr den die Antwoxt auf die Frage "wozu?" "Qui sait?" lautet, ${ }^{13}$ vertritt eine Art heroischen Nihilismu, eine Resignation, die sich mit der Welt zwar njcht versöhnt, aber sich ihr gegenüber dennoch tapfer und resolut hält. Das heisst "schweigen und walten/ wissend, dass sie zerfallt,/ dennoch die schwerter halten/ vor die Stunde der Welt." 14 
I'ART POUR I'́ ART?

In Benns Augen war Nietzsche "... das grösste Ausstrahlungsphänorien der Geistesgeschichte ... der Mensch ohne Inhalt, der die Grundlagen der Ausdruckswelt schuf", ${ }^{1}$ und sein Vorbild, was die Leidenschaft in Fragen dex Form anbelangt. In Anlehnung an Nietzsche spricht Benn von "Artistik", "Ausarruck", MOberfläche", "Schein" und von dem "Olymp des Scheins". Dass diese Terminolotie der Kunst in Nietzsches Werken gangund gëbe ist, J.ässt sich kaum bezweiLeln. Obwohl aber Benn dasselbe Vokabular verwendet, verkennt er den eigent1Hchen Sinn und Zweck Nietzsches, inden er die einzelnen Worte und Ausdriajcke aus dem Zusammenhang reisst und mit ihnen seine eigene Theorie der absoluten Kunst der Form begrindet.

* An mehreren Stellen seines Werkes spricht Benn von der "Kunst an sich", von der "Möglichkeit von geordneten Worten und Sätzen als Kunst", ${ }^{2}$ und stellt die Frage, auf einen Aufsatz von Heinrich Mann hinweisend, ob ein Stiuck Prosa oder ein.Gedicht, unabhängig von dem Inhalt, nicht etwa eine Wirkung hervorbringen könnte, ob nicht "in der Genauigkeit der Wortgefüge, der Seltenheit der Bestandteile; der Glätte der Oberfläche .... eine inpere Tugend, eine Art göttlicher Kraft, etwas Ewiges wie ein Prinzip" liegt. ${ }^{3}$ Benn bejaht die Frage, indem er eine neue Definition von "Artistik" gibt, als "der Versuch der Kunst, innerhalb des allgemeinen Verfalls der Inhalte sich selber als Inhalt zu erleben und aus diesem Erlebnis einen neuen Stil zu bilden", 4 nämlich den Formalismus. An einer anderen Stelle spricht Benn von Artistik als "Fanatismus des Ausdrucks, Virtuosentum grossen Stils". 5 Diese Teminologie ist in den Werken 
.Nietzsches zu finden. Was Benn aber augenfällig verkannt oder übersehen hat, ist die Tatsache, dass solche Ausdrücke bei Nietzsche entweder bire Abwertung bezeichnen, oder aber aIs Polemik gegen die didaktische Kunst und die Kunst als Dienerin der Religion mit einem von der Religion bestimnten Inhalt gedacht werden.

Fin gutes Beispiel fuir die Formel "Fanatismus des Ausdrucks, Virtuosentum grossen stils" als Abwertung bet Nietzsche ist "Nietzsche contra Wagner". In dieser Wagner-Polemik brandmakkt Nietzsche sowohl die französischen Romantiker als auch Wagner alks:

ar Tenatijer des Ausdrucks, grosse Entdeckex Im"Effekte, in der Schaustef1t Iung, In der Kunst der Schauläden ... Virtuosen durch und durch, wit unheimlichen Zugängen zu allem, was verfuhrt, lockt, zwingt, umwirft $\ldots$. begehrlich nach .... allen Opiaten der Sinne und des Verstandes. In ganzen eine verwegen-wagende, prachtvold-gewaltsame ... Art von Kinstlern ... aber krank ...6 6

Das Orteil, das Nietzsche hier fällt, ist nicht zu verkennen: décadence. In Nietzsches Augen ist "Ranatismus des Ausdrucks" Dilettantismus und wirtuosentum des grossen Stils" Stillosigkeit.

Obwohl Nietzsche bei dem Schaffen eines Kunstwerkes grossen Wert auf die. Form legt, obwohl er behauptet: "Man ist um den Preis Klinstler, dass man Das, was alle Nichtkinstler 'Form'nennen, als Inhalt, als 'die Sache selbst' empfindet", 7 bedeutet das bei weitem noch keinen blossen Formalismus. Vielmehr ist es eine Auseinandersetzung mit dex traditionellen christlich-platonischen Anschauung, dass ein Kunstwerk als solches, eine schöne Forn, die entziickt, kein Recht zu existieren hat, es sei denn, dass sie auch einen "guten" oder "wahren" Eintersinn enthält, denn das Schöne muss gleichzeitig auch das Wahre und das Gute sejn. So muss jedes Kunstwerk der tradjtionellen Metaphysik dienen 
und ist in Grunde eine geschminkte Metaphysik. Fir Nietzsche ist aber die Kunst, ohne übersinnlichen Hintersinn, das grosse stimulans zum Leben, indem sie die einzige legitime "Illusionsstufe" darstellt, die zum Leben verführt.

"An einem Philosopher", behauptet er,

... ist es eine Nichtswürigkeit zu sagen, "das Gute und das Schöne sind eins"; fugt er gar noch hinzu "auch das Wahre", so soll man ihn prügeln. "Die Wahrhejt ist hässlich. Wir haben die Kunst, damit wir nicht an der Wahrheit zugxunde gebn. 8

Nietzsche sieht die Kunst als dem Leben unterstellt, und meint, eine schöne Form, die atzuckt und damit zumLeben verfibet, ses gerechtfertigt.

In sem Lob der Griechen dritkt sich Nietzsche úber den Zusanmenhang zwischen des schönen Form und dem Ieben folgendermassen aus:

Oh diese Griechen! sie verstanden sich darauf, zu leben: dazu tut not, tapfer bei der Oberfläche ... stehen zu bleiben, den Schein anzubeten, an Formen, an Töne, an Worte, an den ganzen Olymp des Scheins zu glauben! Diese Griechen waren oberflächlich - aus Tiefe! Und kommen wir nicht eben darauf zurück, wir Wagehalse des Geistes, die wir die höchste und gefährlichste Spitze des gegenwärtigen Denkens erklettert und uns ... von da aus hinabgesehen haben? Sind wir nicht eben darin Griechen? Anbeter der Formen, der Töne, der Worte? Eben darum - Künstler? 9

Hier stellt Nietzsche wieder die Kunst der traditionellen Metaphysik entgegen und meint, wenn man tief denkt und sich nicht anlïgt, dann braucht man eine Illusion, damit man an der Wahrheit nicht zugmande geht. Die Kunst, die das Leben in seine höchsten Rechte einsetzt, ist anbetungswïrdiger als die fietiphysik, die das Ieben verneint.

Die Form wird von Nietzsche nicht vermeint: "das Maß wird Herr, jene Buhe der starken Seele." ${ }^{10}$ Aber eine tunst aus Pessimismis und Nihilismus, einen Formalismus, eine Spaltung zwischen Kunst und Leben mit anschliessender Flucht in den Solipsismus und in die Urzustande, wo man seinen Weltschmerz 
los wird, indem man ihn abbildet, hätte er bestimint nicht begrïsst.

Eine pessimistische Kunst, eine Kunst aus-Pessimismus, ist für Nịtusche eine contradictio in adjecto, il und ex wirft Schopenhauer vor, dieser habe sich eines skandalösen Missverständnisses schuldig gemacht, als er die Kunst als Weg zur Vemeinung des Lebens betrachtete. ${ }^{12}$ Dass Benn aber den Nihilismus als eine innere Realität und den Pessimismus als ein legitimes Prinzip der Seele betrachtet, haben wir bereits erfahren. Dazu meint Nietzsche:

Die Leiduden, Verzweifelten, An-sich-Misstrauischen, die Kranken mitt einem Wowt, haben zu allen Zeiton die entziickenden Visionen nötig gehabt, unes auszuhalten .... Fin verwander Fall: dje Künstier der décadence, wellche im Grunde nihalistisch zum Leben stehen, flibchten in die Schóntieit der Form. 13

Ist Benhs Ästhetik eine Flucht jun die Form, eine Flucht, wie Nietzsche über Wagner sagt, "in die Urzustände"? ${ }^{14}$ Dass Ben den Verlust der prälogischen Geistesart bedauert, liegt auf der Hand. Er sehnt sich nach diesem Zustande und er nennt diejenigen zejter glïcklich, die an eine unbezweifelbare "Wirklichkeit" glaubten, sei es die Religion, die Philosophie oder die Wissenschaft. Fur Benns Generation gibt es keine Wirklichkeit; die alte ist endgijltig verloren und neue Werte gibt es nicht. Diese Generation lebt in einem geistigen quasi-Vakuum, unter Prennung von Geist und Leben. Der Geist flüchtet in den Intellektualișmus, wählt als Haltung die Resignation, den tapferen Nibilismus, aber der Schmerz bleibt. Benn selbst bezeichnet die absolute Kunst der Form als "ein Schritt aus Fliichtlingselend zu einem stundengott". 15 Dass Benns hyperämische Reiche und die Vermischung mit dem Ureinen, zu der sie fuhren, eine Riäckkehr zu den frühen, zu den primitiven Schichten der Psyche bedeuten, haben wir von Benn selbst mit Eilfe von Jaspers im ersten Teil dieser Arbeit erfahren und erörtert. Nietzsche hätte Benns Ästhetik bestimmt eine Flucht 
genannt und Bèn selbst einen décadent, denn während sich der Philosoph um eine neue Wertsetzung als Ersatz für ẳe verlorenen Werte bemühte und ein neues Ziel, das exhöhte Leben aufstellte, dem er die Kunst unterstelite, indem er ihx die Funktion als Stimulans zum Leben gab, isolierte sich der Dich ter vom Leben und das, was er uber Nietzsche schrieb, wurde sein eigenes Verhängnis, nämlich "sein immeres Wesen mit Worten zu zerreissen, der Drang, sich auszudrücken, zu formalieren, zu blenden, zu funkeln ... ohne Rücksicht auf die Ereighisse." 16

In diesem Zusammenhang kommen wir um die Frage nicht herun, ob Benns Esthetik mit el art pour $1^{\prime}$ art" gieichzusetzen ist. Benn selbst verneint die Frage, und swar in seinem "Voxtrag in Knokke", 17 wenn unter I'art pour I'art ein reiner Dilettantismus, ein reines virtuosentum verstanden wird, und be tont, dass seine "Artistik" nicht mit "Ästhetizismu" irn Sinne von "Machen" von Kunstwexken nur um des "Nachens" willen zu verstehen ist. Vielmehr sieht Benn in der artistischen watigkeit, obwohl diese bekanntlich mit keinem höheren Hintersinn im Sinne von einem christljch-platonischien Inhalt verbunden ist, ('I'art pour I'art .... heisst eine Kunst, die keiner Ergänzung von der moralischen oder soziologischen Seite her bedarf". ${ }^{18}$ ) die einzige Erlösung des späten Ich von seiner Iage. Nietzsche wirde dies wohl als das "Gequak kaltgestellter Frösche die jn ihrem sumpe desperieren" bezeichnen, 19 denn bei Nietzsche verfuhrt ja die Kunst zum (erhöhten) Leben. Benn, der Dichter, der kein neues Wertsysten anerkenrt, sieht die Sache wohl anders. Fir ihr ist die Kunst das Stimulans zum Überleben, denn er meint, dass der schöpferische Mensch, "selbst weon ef persönlich und privat von einem geradezu lethargischen Pessimismus befalien seinsolute, durch die latsache, dass er arbeitet, aus 
dem Abgrund steigt. Das angefertigte Werk ist eine Absage gegen Zerfall und Untergang. " 20 
BERTS VERTRAUTHEIT MIT NIETZSCHE

Man fragt sich, warum Benn Nietzsche in Fragen der Kunst und der Philorophie missdeutete und ihn dennoch fast abgöttisch verehrte und als Vorläufer Feiner Ästhetik der Ausảruckswelt betrachtete. Die Antwort auf diese Frage fibt uns Benn selbst, und zwar in seinem Vortrag aus dem Jahre 1950, "Nietztsche - nach fünfzig Jahren". Hier macht. Benn die Bemerkung, dass die Hietzsche-Literatur seit Ende des Ersten Weltkrieges dermassen zugenommen hat, dass it (tes unmöglich ist, auch nur die wichtigsten Bticher zu studieren. Er persönlich findet aber "immer noch am grossartigsten das Buch von Ernst Bertram, "Nietz-sche, Versuch einer Mythologie', erschienen 1918 bei Georg Bondi, am belehrendsten und aufschlussreichsten das von Jaspers, erschienen bei de Gruyter 1936." I Hier liegt der Kern der Missdeutung sowohl auf den Gebiet der Philosophie als auch auf dem der Kunst.

Dass Benn die Philosophie Nietzsches als Philosophie ignoriert hat, wacht er in dem obenerwähnten Vortrag unverkennbar klar. "Verküindete er eine Philosophie? Keineswegs," ${ }^{2}$ hejsst es. Diese Ansicht, die von etwa der Jahrhundertwende und durch vier Jahrzehnte gang und gäbe war, verdanken wir in erster Linie den vielfältigen Benihungen des George-Kreises und dessen exfolgreichsten und meistgelesener Nietzsche-Exponenten - Ernst Bertram.

Vas den George-Kreis betrifft, beschäftigten sich die Mitglieder unter der Fihrung Stefan Georges tatsächlich mit Nietzsche und mit seinem Werk, nur brawchten sie ihn zu ihren eigerien Zwecken: als Grundlagendeponenten einer neuen deutschen Mythologie. Die Mitglieder dieses Kreises, von denen mehrere 
- Professoren an deutschen Universitäten waren und ihren Einfluss als Erzieher von kinftigen Erziehern und Autoren spürbar machten, vereinte ein gemeinsames

4. Bedauern - denn sie waren im Grunde Romantiker - iuber die Entartung der deut-

- schen Sprache zu einem platten Zeitungsstil. Obwohl George Dante ins Deutsche und ein anderes Mitglied, Borchert, denselben Dichter in eine Art von selbstexfuldenem mittelalterlichern Deutsch übersetzte, wurde es ihnen bald klar, f dass die deutsche Sprache nur noch mit Hilfe einer Mythologie zu retten sei.

Als sie sich nach einem Vorbild umschauten, entdeckten sie Nietzsche, und fanden in ihm die Verkörperung der Ablehnung der modernen Pöbelhaftigkeiti. George selbst schrieb Gedichte uber Nietzsche - "Nietzsche" ("Der Siebente Ring"in) und "Einer stand auf" ("Der Stern des Bundes", 1914) - in denen Nietzsche als Zerstörer, als Romantiker, als Retter und Seher gerihmt wird.

Die bekanntesten Mitglieder des Kreises waren der bereits erwähnte Ernst Bertran, Ernst Gundolf und Kurt Hildebrandt. Hildebrandt verfasste, in Zusaramênarbeit mit Gundolf, einen im Jahre 1923 erschienenen Essayband Nietzsche als Richter unserer Zeit", ein Werk, das mit den drei anderen Nietzsche-Bichern Hildebrandts gemeinsam hat, dass es Nietzsches Philosophie kaum erwähnt.

Bertrams magnum opus, "Nietzsche, Versuch einer Mythologie" enthält zwei Wahrheiten schon im Titel - nämlich, dass es ein Versuch ist und dass der Autor zugibt, dass es sich um eine Mythologie handelt und sich damit begnikgt. Wie die übrigen Jünger Georges, so blieb auch Bertram den Idealen seines Meisters treu. In Bertrams Buch, dessen ursprünglich von dem Autor vorgesehener Titel "Masik des Sokrates" (!) war, 3 - mit Goethe-Zitat schon auf der Zueignungsseite - Iormt der Philosophie Nietzsches nur wenig Bedeutung zu. Dafur gibt es aber Kapitel mit Titeln wie "Ahnentafel", "Ritter, Tod und Teufel"s. 
"Arion", "Judas", "Nachsommer", "Claude Lorrain", "Venedig", "Portofino" und "Eleusis", neunzehn Kapitel insgesamt, neun von ihnen mit einem Goethe-Zitat vorangestellt. Das ganze ist in einem schwärmerischen, verwickelten, verzierten Rednerstil geschrieben, wobei die Logik leider ein wenig zu kurz koinmt. Onter vielen anderen werden Elisabeth Förster-Nietzsche, Hölderlin, C.F. Mefer, Hebbel; Stifter, Schopenhauer, Novalis, Jean Paul, Schiller, Bossuet win natirlich auch George zitiert. Wo aber aus Nietzsches Werken zitiert wird, fohr häufig der Fall ist, werden genaue Verweise nicht angegeben und die atate gelegentlich aus dem Zusammenhang gerissen oder aber auch falsch zitiert.

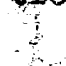

Bereits in der Einleiting; die typischerweise den Titel "Legende" trägt, macht Bertram seine Absichten $\mathrm{klar}$, indem er die Möglichkeit einer wirkljchkeitstreuen Geschichtsschreibung kategorisch ablehnt, mit Worten, die den oftzitierten Goethe zu parodieren scheinen: "Alles Gewesene ist nur ein Gleichnis". 4 "Keine geschichtliche Arbeitsart" fährt er fort,

... verhilft uns ... zum Anblick leibhaftiger Wirklichkeit, Wie sie elgentlich gewesen". Geschichte, zuletzt doch Seelenwissenschaft und Seelenkindung, ist niemals gleichbedeutend mit Wiederherstellung irgendeines Gewesenen, mit der möglichsten Anniherung auch nur an oine gewesene Wirklichkeit. 5

Auf Wissenschaftiichkeit, on als philosophie oder als ceschichtsschreibung, wird also nicht einmal Anspruch gemacht. Seine Methode und seine Absichten begrindet Bertram in der Folgerung: "Was als Geschichte ïbrigbleibt von allem Geschehen, ist immer zuletzt ... die Legende." 6

Bertram erlebt Nietzsche als den "typischen Zweideutigen", 7 und behauptet, er widerspreche sich dauernd. Nietzsche war, laut Bertram, Christ, aber "auf eine heimliche, parodische und widerspruchsvolle Art Christ", er war es 
auch darin; "dass er seine Feinde liebte. Mit einer Liebe freilich, in der christlicher Selbsthass und hellenisch wetteifernder Neid eine echte nietzschesche Vermählung eingehen".

Die biologistisch-darwinistische Hissdeutung des Werke Nietzsches, die wir bei Benn beobachtet haben, wird von Bertram angedeutet, indem er Nietzsche falsch zitiert: "Welch seltsames Bild, dieser Unbedingte und Unwerter der Werte, dem "Dauer auf Erden ein Wert ersten Ranges' ist!" 9 An der zitierten otelie der "Fröhlichen Hissengchaft" spricht Nietzsche von der mittelalterHichen Gesellschaft, die wenigstens Dauer hatte und sagt "Dauer ist auf Erden In Wert ersten Ranges", 10 was Ger ganzen Sache eine völliz andere Färbung gabt. Dieses falsche Zitat ist nicht nur in der ersten, im Jahre 1918 erschienefen Auflage zu finden, sondern auch in der siebten "durchgehen verbesserten und ergänzten Auflage" aus dem Jahre 1929 (21 000 Exemplare) und-auch noch in der achten (postumen) Auflage (1965).

Bertram, wie auch die übrigen Mitglieder des George-Kreises, sah in Nietzsche den Heiligen und erklärte seine gejstige Umachtung nicht als Folge einer Krankheit oder etwa als Missbrauch von Drogen, sondern als Mystik. Das Ietzte Kapitel des Buches, "Hleusis", in dem der Wagner des Tristan als Nietzsches Sinnbild bezeichnet wird ${ }^{11}$ und das dem Klang nach aus der Opsr "Mristan und Isolde" stammen könnte, wirkt wie eine Apotheose und bringt Bertrams Vorliebe für Alliteration und Assonanz besonders deutlich zum Ausdruck. An einer Stelle dieses Kapitels, die fir das ganze typisch ist, schreibt Bertram von Niefzsches Wahn-Hystio:

Bewusst, ein Empedokles, wirft er sich in den Krater der tödlichen Erkenntnis, der mörderisch lockenden Hellsichtigkeit einer logischen Verzilckung und eines zersetzenden Tnthusiasmus. Ausserster eleusin- 
ischer Rausch ist in diesem festlichen Hinabgehen ins Unbetretene, nicht zu Betretende, in dem feierlich trunkenen Stolz des Wissens: "Also begann Zarathustras Ontergang". 12

Geradezu feierlich wirkt die Wendung "ins Unbetretene, nicht zu Betretende". Bertram fährt fort: Geheianisvoll fuhrt das Gewolk des Wahns, in dem ihn sein geistiger Tod, ein Whitod und Opfertod, uberkommt, einen Willigen und fromn Verwandlungssuichtigen hinüber ..." ${ }^{13}$ Herrlich, diese Assonanz in "geheimnisvoll fuhrt das Gewölk des Wahns"! Wie der "Liebestod" in "Tristan und Isolde" 1.jingt die Hulaigung, mit der Bertran das Buch schliesst, immer noch über Metzsches geistige Unnachtung Kommentierend; die er Mystik nennt: "... die touliche Selbstentiuickung, Selbstentrickong in den anflösenden Wahn." I4 Wie wehig es fur Bertram auf Tatsacken, Wissenschaft und Wahrheit, umsomehr aber auf Effekt ankomimt, zeigt sich in seiner in Zweiten Weltkrieg veröfentlichten Verteidigung der Unterdrückung der Redefreiheit, "Von dex Freiheit des Wortes", in der er seine Neigung zur Zweideutigkeit zeigt, indem er behauptet, die echteste Freiheit sei die Unfreiheit. 15

Das Gefährlichste an Bertrams Werk war sein Einfluss. In der Nachwort zur chten Auflage (I965) schreibt Hartmut Buchner:

Die schöpferische Virkung des Buches bis in die höchsten geistigen, vor allem dichterischen and Hiterarischen demaligen Produktionen unseres Landes hinein und daruber hinaus war erstaunlich (George, Gundolf, Th. Hann, Benn, Gide u.a.) und sollte uns, gegenüber heute gern und allzu billig geubten Aburteilungen oder auch nux Vermenglimpfungen dieses Werkes stutzig machen ... 16

Buchner weist darauf hin, dass Bertram in erster linie ja Dichter war (wie Benn), und dass man es ihm kaum übel nehmen kann, dass er Náetzsche als Philosophen "nicht immer gerecht wird und werden konnte". 17 Das ist ohne Zwelfel. wahr, und man kann es Thomas Mann ebensowenig ibel nehmen, dass er Bertrams 
Buch das schönste über Nietzsche fand. ${ }^{18}$ Das war einfach die Lage in der damaligen Zeit: die Nietzsche-Iegende, die schon mit der "mysteriösen" elf jährigen geistigen Umachtung Nietzsches begann, ubexschattete seine Philosophie. 3. Der Legende von Nietzsche als Martyrer, als HeiJiger und Mystiker einerWeits, and anderenseits der Missdeutung seiner eigentlichen Philosophie im biologistisch-darwinistischeỏ Sinne wurde von seiner Schwester Elisabeth För8ter-Mietzsche Vorschub geleistet, und zwar dadurch, dass sie manche seiner Hachlasswerke, zu denen sie ausschliessliche Rechte hatte, immer wieder in Feuren Ausgaben mit ihren eigenen Vorwort veröffentlichte, manche dagegen Wot viele Jahre nach dem Tode ihres Bruders. Inr Einfluss war gross, denn Hie behauptete, dass diejenigen Werke, die die eigentliche Philosophie ihres Bruders verkünden, noch in ihrem Besitz (unveröffentlicht) seien, und sie sohien sich immer besser daran zu erinnem, was Nietzsche ihr über sein Werk gesagt hatte. Es schien sie auch nicht zu stören, dass der Mann, mit dem sie verheiratet gewesen war, ein Apostel des Anti-Semitismus war, gegen den Nietzsche sein Leben lang polemisiert hatte. So kam es, dass ein Darwin-bewusstes Zeitaltex Nietzsches Übexmenschen biologistisch-darwinistisch auslegte, dem "Ecce-Homo", die eindeutige Wjderlegung des Darwinismus, murde, dank Frau Förster-Mietzsche, erst 1908 veröffentlicht, und dann nur in einer teuren, be. schränkten Ausgabe. Inzwischen hatte die darwinistische Deutung des Übermenschen schon Fuss gefasst. Bald darauf brach der Erste Weltkrieg aus, wäh-rend dessen die Nietzsche-Forschung vernachlässigt wurde, obwohl ein Exemplar von "Larathustra" in jedem SoIdatenformister als Schützengrabenlektiure zi finden war. Da "Zarathustra" bekanntich nicht die geeignetste Einführing in die Philosojhie Nietzsches ist, kann man sich nicht wundern, dass die Ausdrücke 
"Übermensch" und "Blonde Bestie" wie ein Wagnersches "WaIlawaleia" zu Jubelmufen des Nationalstolzes und des wachsenden Positivismus wurden.

So wurden Hissdeutungen von und Vorurteile gegen Wietzsches Cedanken geformt, Vorurteile, die erst nach dem Zweiten Weltkrieg widerlegt wurden. Von der Heiligsprechung Nietzsches von den Mitgliedern des George-Kreises und Frau Förster-Nietzsche und der Missdeutung seiner Werke vor dem Ersten Weltkrieg zu der bewussten Verfälschung seiner Ideen seitens der NationalsozialHoten war nur ein kurzer schritt, den die Grundlage war schon da. Ausserdem. tuss es für Professor Alfred Bäumler, den die Nazis nach Berlin beriefen, um Getzsche in einem nationalsozialistischen licht auszulegen, ficht allzu sothwer gewesen sein, mit Hilfe von falschen Zitaten Ausdrücke wie "Der Wille zur Macht", "Herrenmoral" und "ijbermensch" so zu deuten, dass sie den Zwecken des Nationalsozialismus dienten, Nietzsches eigentlichen Absichten aber direkt widersprachen. Dass Nietzsche solche Schwierigkeiten voraussah, deutet eine Stelle" aus dem "Versuch einer Selbstkritik" an, den Nietzsche 1886 zu der "Geburt der Tragödie" schrieb. In dieser Selbstkritik bernerkt Hietzsche, dass die alte Terminologie seinen neuen Ideen nicht immer gerecht wird:

We sehr bedauere ich es jelizt, dass ich damals noch nicht den Mut (oder die Unbescheidenheit?) hatte, um mir in jedem Betrachte fur so eigne Anschauunger und Wagnisse auch eine eigne Sprache zu erlauben, - dass ich mühselig mit Schopenhawerischen und Kantischen Formeln fremde und neue Wertschätzungen auszudricken suchte, welche dem Geiste Kantens und Schppenhauers, ebenso wie ihren Geschmacke von Grunde aus entgegen gingen. I9.

Dieses gilt um so mehr für die späteren Werke Nletzsches, in denen es sich wicht um seine. Kunstlehre, sondern um die Lehre von dem Übermenschen und die Metaphysik des Willens zur Macht handelt. Frst nach dem Abschluss des Zweiten Weltkrieges begann die wissenschaftiche Nietzsche-Forschung zur Geltung zu 
.r Kommen. Obwohl das orste bedeutende und wissenschaftliche allgemein anexkannte Werk uiber die Philosophie Nietzsches, das von Karl Jaspers, in Jahre 1936 erschien, wurde das magnum opus, das zweibändige Verk von Martin Heidegger erst am Anfang dieses Jahrzehnts, 1961 verfasst. Viele mussten Vorurteile über Nietzsche iberwinden und vollbrachten es, Manche, wie Gottfried Benn, der in erster Linie Dichter war, fielen und fallen immer noch dem Werk des Dichters Ernst Bertram zum Opfer, der in Nietzsche wiederum den Mystiker thond vor allem den Dichter sieht und preist.

(5ie hervorgehenden Benerkungen über das Bertramsche Werk und die Nietztoche-Legende solien zur ErJäuterung von Benns übersehen der Tatsache beiAogen, dass Nietzsche in erster Linte Philosoph war, dass er eine Art philosophisches Systern schuf, wenn auch kein tradjtionelles. Das andere Werk iher Nietżsche, von dem Bem besonders stark beeinflusst wurde, ist das von ihm als das belehrendste und aufschlussreichste bezeichnete Werk von Jaspers. Obwohl Jaspers das Verdienst hat, Nietzsche schon im Jahre 1936 als Fhilosophen erkannt zu haben, ist seine Bemerkung über Nietzsches "Zweideutigkeit" irreführend, ${ }^{20}$ denn Jaspers aint, man solle bei der Lektüre der Nietzscheschen Aphorismen nicht bruchstickweise lesen, sondern sich nicht eher zufrieden geben, his man zu einer jeweiligen Behauptung auch deren widerspmuch gefunden hat. 21 ObwohI bei Jaspers das Wort "zweideutig" mehrere Bedeutungen zu haben scheint - unter anderem kann man damuter verstehen, dass ein Aphorismus gelegentlich eine vielschichtige Bedeutung haben kann, odex man kann darunter eine Paradoxie verstehen - ist jedoch nicht zu verkennen, dass Jaspers, yenn er von Nietzsches "Zweideatigkeit und Vieldeutigkeit" spricht, tatsächlich das traditionelle Vorurteil vertritt, dass Nietzsche sich widerspricht. Wenn man 
nun auf Widersprüche aus ist, so findet man sie auch, obwohl sich die scheinbaren Widerspriiche aufklären, sobald man den Zusammenhang in Betracht zieht. Ein klares und eklatantes Beispiel wäre Nietzsches Gebrauch des Wortes "Metaphysik" oder "metaphysisch". Auf den ersten Blick erscheint es unklar, ob. Nietzsche die Hetaphysik ablehnen will oder sie bejaht. Einerseits scheint. Nietzsche gegen die Metaphysik zu polemisieren. Er nemnt das Christentum "eine Metaphysik des Henkers", 22 lehnt die "priesterlichen und metaphysischen-Verketzerungen der Sinne"ab, ${ }^{23}$ will "alle metaphysische Trösterei zum Teufel schicken - und die Hetaphysik voran", 24 fordert eine "anti-metaphysische Weltbetrachting - ja, aber eine artistische" ${ }^{25}$ und nennt die "Metaphysik, die Noral, die Religion, die Wissenschaft ... verschiedene Formen der liuge". 26 Andererseits "spricht er mrmals von dem "metaphysischen Trost der Mragödie","? bezeichnet den Willen zua Schein, zur Kunst als "tiefer, ursprünglicher, "metephysischer'als der Wilte zur ... Wirklichkeit", ${ }^{28}$ und nennt die "Kunst - und nicht die Moral ... die eigentliche metaphysische Tätigkeit des Menschen." 29 Wenn wir aber bedenken, dass Nietzsche das Wort "Metaphysik" in den Fällen, in denen er gegen sie polemisiert, mit Moral fleichsetat, dass er dabei also Metaphysik in christlich-platonischen Sinne meint, in den arderen Fällen aber von seiner eigenen diesseitsbezogenen Metaphysik spricht, die wix bereits erörtert haben, so wird uns klar, dass es sich nicht um einen Widerspruch handelt, vielnehr um eine terminologische schwierigkejt, die aber wieder betont, dass man Nietzsches Worte nicht aus dem Zusammenhang reissen darf..

Wir haben in dieser Abhandlung versucht, die allgemeine Grundlagenkrise zu schildern, in der sich der Dichter Benn und der Philosoph Nietzsche befaniden, und haben erörtert, wàe die beiden mit der Krịse fertigzuwerden bemüht 
waren. In den Bemiihungen beider nimmt die Kunst eine ausschlaggebende Rolle ein, und beide sehen in ihr die Rettung und Lösung in dem Verfall der traditionellen Werte. Es ist aber aufschlussreich, wie Aussagen, die dem Wortlaut nach dasselbe zu sagen scheinen, im Koritext betrachtet zwei grundverschiedenen Auffassungen zugrunde liegen können. Zwar bezieht sich Benn häufig auf Nietzsche und eignet sich dessen Kunstvokabular an, aber im Grunde sind es twei verschiedene Wege, die Benn und Hietzsche gehen, und sie kommen auch zu Wrerschiedenen Ergebnissen. Wie wir erörtert haben, fasst Nietzsche die Kunst pim weiteren, Benn aker im engeren Sinne des Wortes auf. Fir Nietasche ist die Kunst ein Mittel, das den eigentijchen Zweck, dem "erhöhten Leben" dient, wo7. Hisngegen fur Benn die Kunst als eine Hucht betrachtet und un ihrer selbst willen betrieben wird.

- Der Unterschied zwischen Benns und Nietzsches Auffassung der Rolle der Kunst wurzelt darin, dass Nietzsche den europäischen Nihilismus als überwindbar sieht, während Benn eine durchaus resignierte Hal tung dazu vertritt und ihn nur kïnstlerisch ausnïtzen zu können meint. Nietzsches Haltung ist dynamisch-revolutionär, Benns statisch-quietistisch. Fir Nietzsche stelilen Geist und Leben eine Polarität dar, die im Übermensch-Ideal zur Synthese, zur TotaIität werden, während für Benn Geist und Ieben eine uniberbriickbare Antinomie sind und bleiben missen und eine bewusste Selbstaufspal tung notwendig wird. 


\section{ANMERKUNGEN}

\section{EINLEITUNG}

${ }^{1}$ cottfried Benn, "Ausgewählte Briefe" (Wiesbaden, 1957), S. 172.

"Zuichtung II", III, s. 860 .

3IV, s. 1057.

4"Kunst und Drittes Reich", III, S. 871. "Rede auf Heinrich Henn", IV, 15. 977. "Nietzsche - nach funfrig Jahren", IV, S. 1053. "Brobleme der Iytik", AV, S. 1065, 1091. "Roman des Phinotyp", V, S. 1376. "Dopoelleben", VIII, S. 2030. "Briefe", S. 104 (1946 an Nele Sorensen-Benn).

5 "porische Ielt", III, S. 854. "Roman des Phänotyp", V, S. 1341. "Isebensweg eines Intellektuafisten", VIII, S= 1931.

"Heinrich Ham zari sechiggsten Geburtstag", III, S. 694. "Ziuchtung I", II , S. 779. "Hepressiontbous", III, S. 811. "Rede auf Heinrich Mann", IV, S. 979. Trobleme der Lyrikn, IV, s. 1064. "Roman des Phänotyp", V, S. 1341. ". "Fanst 1 squs zurn Aisdruck" VII, 5. 1692. "Lebensweg eines Intellektualisten", VII, S, 1920. nBriefe", 6. 76 (an Egon Vietta, 1936).

PROGRESSIVE ZEREBRATION UND VERLIST DES PRÄLOGISCHEN ZUSTANDES

Inprovoziertes Lebent, III, S. 899.

2Lacien Iévy-Bruhl, nde geistige Welt der Primitiven" (Miinchen 1927), S. 353 .

Bad., s. $5,12,18$

4 "Gebührt Carleton ein Denkmal?", III, S. 772.

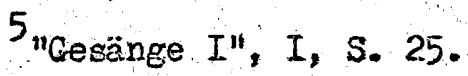

"Nach dein Nihilismus", III, S. 7I4, 717.

7.bd., S. 714 .

8" "Der Aufbau der Persönlichkeit", III, S. 659: "Die biologische Grund- 
'lage der Persönlichkeit ist nicht, wie eine frühere wissenschaftliche Periode annahm, das Grosshirn, sondexn der ganze Organismus.".

9 Vgl., "Der Aufbau dex Persönlichkeit", III, S. 660.

${ }^{10}$ Vgl., "Akademie-Rede", IV, S. 1002.

$1 I_{\text {Elmar Haller, "Gottfried Benn: Die Entwicklung seiner Weltanschaung }}$ in frühen Werk" (Dormbirn 1965), S. 156.'

12 "Nach dem Nihilismus", III, S. 717,ff.

13 "Verlorenes Ich", I, S. 215.

${ }^{14} \mathrm{VI}$, S. 1579 .

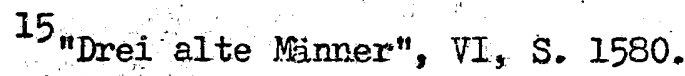

16 Reinhold Grimm, "Die Kunst im Schatten des Gottes" (Göttingen 1962), s. 63 ff.

I7 Vgl. "Die hyperämischen Reiche", I, S. 125. "Dex Sänger", I, S. 59. "Kunst und Staat", III, S. 610. "Zur Problematik des Dichterischen" III, S. 644. "Erobleme der Iyrik", IV, s. 1076. "Der Garten von Arles", V, S. 1257. "Alexanderatige mittels Waliungen", $\nabla$, S. $1277 \mathrm{f}$. "Epilog und lyrisches Ieh", VIII, S. 1879. "Lebensweg eines Intellektualisten", VIII, S. 1914.

18 Elmar Haller, S. 126.

${ }^{19}$ C.G. Jung, "Psychologische Typen" (Zurich 1942), S. 648.

20 "Der Garten von Arles", V, S. 1257. i.:

\section{WIRKLICHKEITSBILDUNG: UND - ZUSAMHENBRUCH}

$I_{\text {"Provoziertes Leben", III, S. } 899 .}$

2 "Kunst und Drittes Reich", III, S. 873.

3Ed., S. 873. Vgl. "Weinhaus Wolf", V, S. 1319.

4VI. Weinhaus Wolf", V, S. 1319. "Fïguren", VII, S. 1727. "Ziichtung II", III, S. 859. "Nach dem Nihilismus", III, S. 721. "Nietzsche - nach finfzig Jahren", IV, S. 1047. "Die neue Iiterarische Seison", IV, S. 993.

5gl. "Doppelleben", VIII, S. 1946. 
6bd., S. 1944.

7 "Lebensweg eines Intellektualisten", VIII, S. 1922. Fỉr ähnliche Äusserungen über Kunst und Staat, Kunst und Rasse, Kunst und Macht, siehe: "Dorische WeIt", 1933, III, S. 850 ff. und "Züchtung I", 1933, III, S. 776 ff.

${ }^{8} \mathrm{Vgl}$. "Kunst und Drittes Reich", III, S. 877: Um 1932 wuxde in Europa der Gedanke einer Mittelmeerakademie Iebendig. "Aber die Einladungen nach Deutschland verfielen der Geheimen Staatspolizei. Die Kunst wurde geschlossen" s. 879. "Der Kinstler wird wieder in die Ordnung der Zünfte zurückgewiesen, aus der er sich um 1600 befreit hatte. Er wird als Handwerker angesehen, ein besonders sinnloser und bestechlicher Handwerker, Auftraggeber ist der Zellenobmainn oder das Soldatenheim."

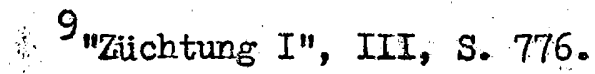

10 "Dorische Welt", III, S. 852.

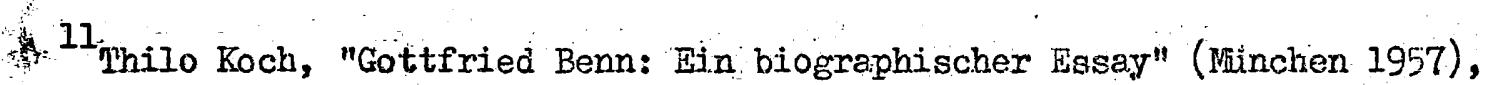
S. 45 .

12 "Briefe", S. 58 (1934 an Ina Seidel): "Gewisse Dinge haben mir den letzten Stoss gegeben. Schauerliche Tragödie! Das ganze kommt mir allmahilich vor wie eine Schmiere, die fortwährend "Faust" ankindigt, aber die Besetzung reicht nur für "Husarenfieber". Wie gross fing das an, wie dreckig sieht es heute aus. Aber es ist noch lange nicht zu Ende."

\section{3 "Doppelleben", VIII, S. 1960. \\ 14 "Der Geburtstag", V, S. 1228.}

\section{METAPHYSISCHER VIRRAT}

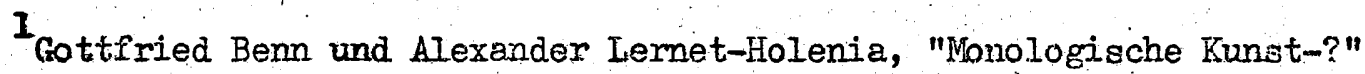
(Wiesbaden 1953), s. 25.

2 "Wir gerieten in ein Mohnfeld", I, S. 22.

3 "Briefe", (1952 an Edgar Lohrer) S. 228.

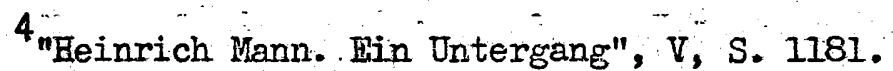

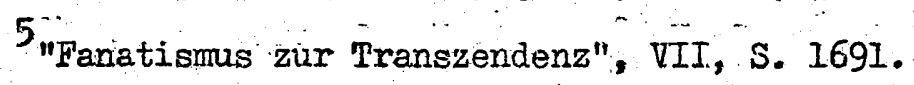

"Akademie-Rede", IV, S. I000-1. 
7Vgl., "Der Aufbau der Persönlichjkeit", III, S. 655-8.

VERLUST DER KONTINUIERLICHEN PSYCHOLOGIE

I"Lebensweg eines Intellektualisten", VIII, S. 1896.

2 "Der Geburtstag", V, S. 1220.

3."Die Reise", V, S. 1203.

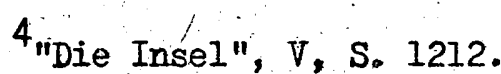

5 Ebd., S. 1212.

7f "Lebensweg eines Intellekturlisten", VIII, s. 1910.

DIE ANTINONIS VON GEIST UND LEBEN

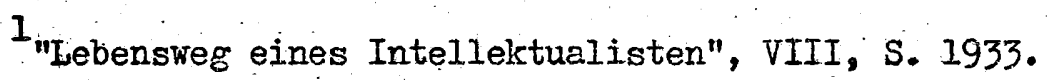

"Der Ptolemäer", V, S. 1387.

3"Monologische Kunst-?", s. 22 f: " ... diese Stimme hinter dem Vorhang ... will sagen, lasst doch euer ewiges ideologisches Geschwätz, euer Gebärme un etwas 'Höheres', der Mensch ist kein höheres Wesen, wir sind nicht das Geschlecht, das aus dem Dunkel ins Helle strebt - wohin wir streben, weiss ich offen gestanden nicht, aber was wir erreichten, war in weitem Umfang das Überhebliche, das Hybride, auch das Dumme."

4"Pallas", III, S. 927. Vgt. "Doppelleben", VIII, S. 1994.

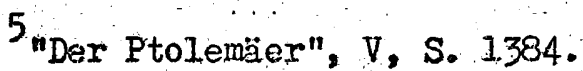

Ebd., S. 1428.

"Doppelleben", VIII, S. 2008.

DAS BIONEGATIVE

1VgI., "Das Genieproblem", III, S. 682. "Thust und Drittes Reich", III, S. 870. "Provoziertes Leben", III, S. 905. "Altem als Problem fuir Kiinstler", IV, S. 1134. 
2Vgl., Elsa Buddeberg, "Gottfried Benn" (Stütgart 1961).

3. Whelm Lange-Eichbaum, "Genie - Irrsinn und Ruhm" (Nincien 1935), s.

11.

4"Das Genieproblem", III, S. 6\%4.

5 "Der Aufbau der Persönlichkeit", III, S. 655-658.

6ange-Richbaum, S. 265.

7 "Provoziertes Ieben", III, S. 905.

8mach dem Nihilismus", III, S. 721.

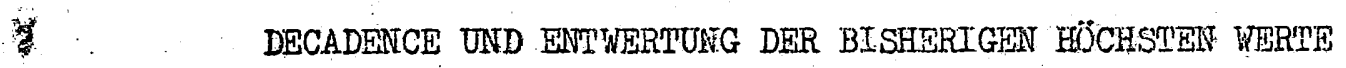

I WeM., Vorrede: Aph. 3 .

2WzM., Aph. 200.

${ }^{3}$ Vgl., WzM., Aph. 427 .

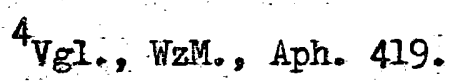

${ }^{5} \mathrm{Vgl}$, Aph. 407, WzM.

6., Aph. 1-7.

7.W., Aph. 2.

DIE AXIOLOGISCHE AOSEINANDERSETZUNG

$I_{\text {wach dem Nihilismus", III, S. } 723 .}$

2.H., Vorwort, Aph. 2.

3Ed., Aph. 3

4 wrM., Aph. 579 .

5 Nartin Heidegger, "Nietzsche" (PfulIingen 1961), I, S. 489.

${ }^{6}$ GaT., S. 35 . 
7.WM., Aph. 1047 .

8zl4., Aph., 10461 .

9 WzM, Aph. 10463 .

10., Aph. 21 .

11 Ebd., Aph. 22.

12 Bitte um Verzeihung. Ich konnte der Versuchung nicht widerstehen, 13 NeW., S. 131 .

NFETZSCHES METAPHYSIK DES WLILENS ZUR MACHT

1.Mz., Aph. 689.

2 Ed., Aph. 46.

${ }^{3}$ Vgl., Z., Kapitel 12 "Von der Selbstiberwindung".

${ }^{4}$ DdW., I, Aph. 81.

KUNST UND DAS ERHÖHTE IEBEN BEI NIETZSCHE

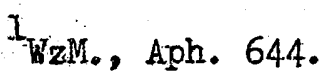

2.M., Aph. 820.

3"Nach den Nihilismus" (1932), III, S. 721. Weinhaus Wolf" (1937), IV, s. 1319. "Zilchtung II" (1940), III, s. 859. "Figuren" (1940), VII, S. 1727. "Die neue literarische Saison" (1941), IV, S. 993. "Nietzsche - nach funfuig Jahren" (1950), IV, S. 1047 .

III, 3. 721 .

E.H., "Warum ich so gute Bitcher schreibe", 1 .

6 Iudwig Giesz, "Wietzsche: Existentialismus und Wille zur Nacht" (Stuttgart 1950), S. 135 .

7 UB., "Schopenhauer als Erzieher", Aph. 5.

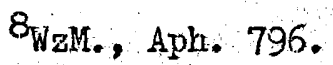


${ }^{9} \mathrm{Gar} .$, s. 129.

10 UdW., I, Aph. 80.

11 Heidegger, I, S. 95.

12 Ebd., I, S. $616 \mathrm{f}$.

${ }^{13}$ Bruno Hillebrand, "Artistik und Auftrag" (Mianchen 1966), S.126.

${ }^{14}$ Fur die Ausdrücke "Glaubensbekenntnis" und "Artisten-Evangelium" siehe WzM., Aph. 853 IV.

H. ${ }^{15}$ GdT., Vorwort an Richard Wagner. Nietzsche zitiert diesen Satz in WzM., Aph. 853 IV.

16 GdT., "Versuch einer Selbstkritik", S. 35.

, $\quad 17$ G., S. 89 .

18 Wa., Aph. 853 II.

* 19 "Lebensweg eines Intellektualisten", VIII, S. 1920. "Briefe" (1936 an Bgon Vietta), S. 76 .

20 "Expressionismus", III, S. 8II.

21 "Rede auf Heinrich Mann", IV, S. 979.

${ }^{22} \mathrm{GdT}$., S. 71 f. Es bestehen Variationen wie "das Dasein der Welt" anstatt "das Dasein und die Welt", die den Sinn jedoch nicht wesentlich ändern.

KOWSY UND WAHRHEIT BEI NIETZSCHE

1E.H., Vorwort, Aph. 3.

2 Heidegger, s. 89.

3.M., Aph. 493.

4 GdT., s. 146 f.

5 Der Ausdruck "Olynap des Scheins" erscheint bei Nietzsche zum ersten MaI jn der Vorrede zur 2. Ausgabe der "Fröhlichen Wissenschaft" (1886). Drei Jahre später erscheint es als Abschluss zu "Nietzsche contra Wagner".

ENeW, S. 130 . 
$7_{\text {WzM. }}$, Aph. 804.

8 WzM., Aph. 808.

9 Hillebrand, S. 126.

${ }^{10}$ WzH. $_{\text {, Aph. }} 853$ III.

${ }^{11} G_{0}$, S. 88.

12 WzH., Aph. 801.

13 wzM., Áph. 809.

${ }^{14}$ UdW., Aph. 78.

15 WzM., Aph. 822.

${ }^{16}$ CaT., S. 138

17 Ebd.

${ }^{18}$ G., S. 94 .

BENN UND DIE MONOLOGISCH-MONOMANE KUNST

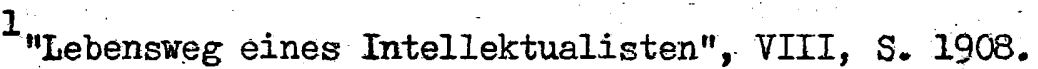

"Doppelleben", VIII, S. 2032.

3"Soll die Dichtung das Leben bessern?", IV, s. 1156. Vgl. "Probieme der Iyrik", IV, S. 1066.

${ }^{4}$ Der Ausdruck "monologische Kunst" stamnt von Nietzsche ("Fröhliche "Wissenschaft") und ist der Cegensatz zu "Kunst vor Zeugen".

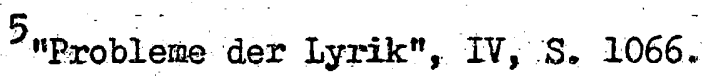

6 "Dorische WeIt", III, S. 856.

7 Ebd.

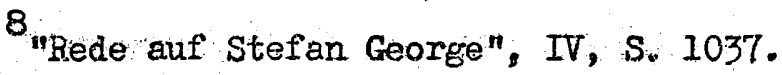

9 "Akademie-Rede", IV, S. 1002.

10 "Lebensweg eines Intellektualisten", VIII, S. 1908. 
${ }^{11}$ "Rede auf Heinrich Mann", IV, S. 980.

12 "Querschnitt"; V, S. 1249.

${ }^{13} \mathrm{Vgl.} \mathrm{"Fanatismus} \mathrm{zur} \mathrm{Transzendenz",} \mathrm{VIII,} \mathrm{s.} 1691$.

14 "Nacht", I, S. 85.

15 "Lebensweg eines Intellektualisten", VIII, S. 1920.

$16_{\text {Ebd., S. } 1932 .}$

17 "Zur Problematik des Dichterischen", III, S. 643.

18 "Akademie-Rede", IV, S. 100 .

${ }^{19}$ Haller, S. 157.

BENINS AUSDRUCKSWEIIT

* "Briefe" (1950) an Dieter Wellershoff, S. 204.

2 "Schädelstätten", I, S. 78.

$3^{3}$ Schöpferische Konfession", VII, S. 1645.

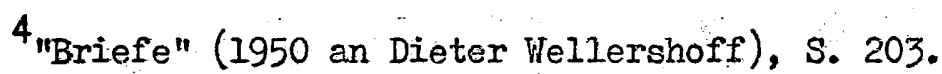

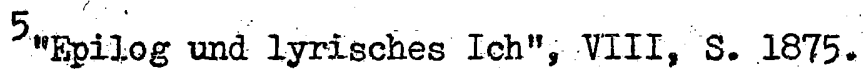

"6riefe" (1950 an Dieter Weilershoff), S. 202.

7 "Untergrundbahn", I, S. 31 .

8 "Lebensweg eines Intellektualisten", VIII, s. 1910:

RESIGNATION UND ANOR FATI

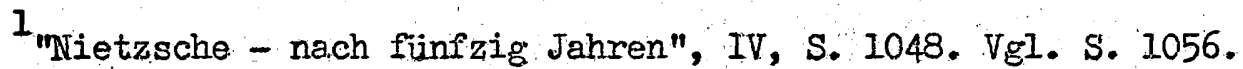

"Monologische Kunst-?", S. 18. VgI. "Nietzsche - nach fünfzi-g Jahren", IV, S. 1053.

3 Ebd. 
"kunst und Drittes Reich", III, s. 874. Vgl. "Weinhaus Wolf", V, s. 1319.

${ }^{5}$ G., "Wie die 'Wahre Welt' endlich zur Fabel murde", S. 61.

6gl. G., S. 124

7 WzH., Aph. 45 .

8 A., Aph. 9 .

9 WzM., Aph. 2.

10 "Expressionismus", III, S. 808.

1I "Zum Thema Geschichte", III, S. 950.

12 mparginalien", III, S. 961.

13 "Qui Sait", I, S. 80.

14 "Dennoch die Schwerter halten", I, S. 182.

\section{I'ART POUR I'ART?}

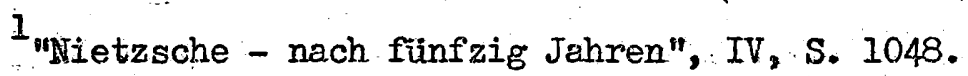

2 "Doppelleben", VIII, S. 1998.

3 "Rede auf Heinrich Mann", IV, S. 976. Der Aufsatz, auf den hingewiesen wird, ist "Die Kunst" in dem. Essayband "Geist und Tat".

4 "Frobleme der Lyrik", IV, S. 1064.

5 "Heinrich Mann zum 60. Geburtstag", III, S. 694.

6 $\mathrm{NeH.}$. S. 139

7 WzM., Aph. 818.

8. WE., Aph. 822.

9.W., Vorrede. NcW., Epilog, Aph. 2.

10 WzM., Aph. 819.

II WzM., Aph. 821. 
12 WzM.; Aph. 812 .

13 WZM., Aph. 852.

14 WzM., Aph. 92.

15 "Zum Problem des Dichterischen", III, S. 643.

16 "Probleme der Lyrik", IV, S. 1065.

17 "Vortrag in Knokke", IV, S. 1112.

18 "Rede auf stêfan George", IV, S. 1038.

19 WzM., Aph. 808 .

20 "Marginalien", III, S. 962.

\section{BENNS VERTRAUTHEIT MIT NIETZSCHE}

Inietzsche - nach fünfzig Jahren", IV, S. 1047.

2Ebd., S. 1052.

${ }^{3}$ George riet ihm davon $a b$.

4monst Bertram, "Nietzsche, Versuch einer Ifythologie", 8. Auflage (Bonn 1965), S. 9.

5 Ebd.

$6_{\mathrm{Fbd}}$.

7 Bertram, s. 16.

8 Bertram, S. 318.

9 Bertram, S. 20.

${ }^{10}{ }_{\text {FW., Aph. } 356 .}$

II Bertram, S. 370 .

12 Bertram, s. 370.

13 Ebd. 
95

${ }^{14}$ Bertram, s. 372 .

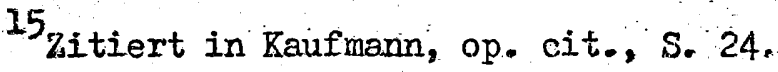

${ }^{16}$ Bertram, Nachwort von Hartmut Büchner, S. 402.

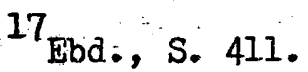

18 Thomas Manr, "Rede über Nietzsche" in "Bemihunger1", S. 335.

19 Gdis., "Versuch einer Selbstkritik", s. 38 .

${ }^{20}$ Karl Jaspers, Wietzsche: Einfürung in das Verständnis seines Philosophierens" (Berlin 1936), S. 8 f. und s. 368 .

$21_{\text {Ebd., S. } 8 .}$

22 G., S. 73.

23 WzM., Aph. 820.

$24 \mathrm{GdT}$. S. 41 .

25 WzM., Aph. 1048.

26 Ebd., Aph. 853 I.

27 GdT,, s. 146 f, s. 138 , s. 139 , s. 150.

28 WzM., Aph. 853 III.

29 GaT., S. 35. Vgl. WzM., Aph. 853 IV. 
BIBLIOGRAPHIS

Benn, Gottfried: "Ausgewählte Briefe". Mit einem Nachwort von Max Rychner. Wiesbaden (Iimes). 1957.

Benn, Gottfried: "Gesammelte Werke" in 8 Bänden, herausgegeben' von Dieter Wellershoff. Wiesbaden (Limes) 1968.

Benn, Gottfried und Alexander Lemet-Holenia: "Monologische Kunst-? Ein Briefwechsel zwischen Allexander Jernet-Holenia und Cottfried Benn". Wiesbaden (Iimes) 1953.

Bertram, Winst: "Vietzsche. Versuch einer Mythologie". 8. Auflage. Bonn (Bouviers 1965.

Economo, Heline Freifrau von: "Constantin Freiherr von Economo. Sein Leben und Wirken, Brzählt von seiner Frau und von Julius von Wagner-Jauregg". Enthalt auch "Probleme der Hirnforschung". Wien (Mayer) 1934.

Friedrich, Hugo: "Die Struktur dex modernen Lyrik". Reinbeck bei Harburg (Rowohlt) 1956.

Giesz, Ludwig: Wietzsche: Hxistentialismus und Wille zur Macht". Stuttgart (Deutsche Verlags-Anstal.t) 1950.

Grimn, Reinhold und Wolf-Dieter Marsch: "Die Kunst im Schatten des Coties. Fir und wider Gottfried Benn". Göttingen (Sochse und Pohl) 1962.

Guardini, Rornano: "Ưber das Wesen des Kunstwerks". Stuttgart-Tübingen (Rainer Wunderlich) 1948.

Haller, Elmar: "Gottfried Benn: Die Entwicklung seiner Weltanschaung in frihen Werk". Dornbirn (Vorarlberger Verlagsanstalt) 1965 (Diss.).

Heidegger, Martin: "Nietzsche". Pfullingen (Neske) 1961.

Hillebrand, Bruno: "Artistik und Auftrag". Ninchen (Nymphenburger Verlagshandlung) 1966.

Hohoff, Curt: "Geist und Ursprung". Minchen (Ehrenwirth) 1954.

Holthusen, Hans Dgon: "Der unbohauste Mensch: Notive und Probleme der modernen Literatur". Minchen (DIV) 1964.

Holthusen, Hans Egon und Friedhelm Kemp (Herausgeber): "Ergriffenes Dasein. 
Deutsche-Iyrik des zwanzigsten Jahrhunderts". 11. Auflage. Ebenhausen bei Mhinchen (Hartfrid Voss) 1965.

Jaspers, Karl: Mpjetzsche: Einfuhrung in das Verständnis seines Philosophierens". Berlin (de Gruyter und Co.) 1936.

Jung, C.G.: "Psychologische Typen". Zürich (Rascher und Cie.) 1921.

Kaufmann, Walter: "Nietzsche". Cleveland (The World Publishing Co.) 1966.

Koch, Thilo: "Gottfried Benn: Ein biographischer Essay". Minchen (Albert Langen/Georg viiller) 1957.

Kunisch, Hermann: "Die deutsche Gegenwartsdichtung: Kräfte und Formen". Niinchen (Nymphenburger Verlagshandlung) 1968.

Lange-Eichbaxt, WilheIm: "Genie - Irrsinn und Ruhm". 2. Auflage, Minchen (bei Ernst Reinhardt Verlag) 1935.

Ienning, Walter: "Gottfried Benn in Selbstzeugnissen und Bilddolumenter". Reinbeck bei Hamburg (Rowohlt) 1966. 6. Auflage.

Lévy-Bruhl, Eucien: "Die geistige Welt der Primitiven". Minchen (F. Bruckmann A.G.) 1927 .

Lévy-Bruhl, Iucien; "L' ame Primitive". Paris (Librairie F'lix Alcan) I927.

Iison, Ferdinand: "Lebensquellen der deutschen Metaphysik", Frankfurt am Main (Vittorio Klostermann) 1960.

Lohner, Edgar: "Expressionismus:" Gestalten einer literarischen Bewegung". Heidelberg 1956.

Lohner, Edgar: "Passion und Intellekt: Die Lyrik Gottrxied Benns". BerlinSpandau (Iuchterhand) 1961.

Loose, Gerhard: "Die Ästhetik Gottfried Benns". Frankfurt am Mein (Vittorio klostermann) 1961.

Menn, Thomas: "Thomas Mann an Ernst Bertram. Bxiefe aus den Jahren 1910-55". Pfullingen (Neske) 1960.

Niedemayer, Max und Niarguerite Schliuter, Herausgeber: "Das Cottfried Benn Buch". Frankfurt am Main (Fischer) 1968.

Nietzsche, Friedrich: MDie Geburt der Tragödie aus dem Geist der Musik". Herausgegeben und mit einem Nachwort von Alfred Bäumler. Stuttgart (Kröner) 1955. 
Nietzsche, Friedrich: Mnzeitgemässe Betrachtungen". Manchen (Goldmann) 1964. Wietzsche, Friedrich: Wenschliches, Allzumenschliches". Whinchen (Goldmann) 1964.

Nietzsche, Friedrich: "Die fröhliche Wissenschaft". Winchen (Goldmann) 1964.

Nietzsche, Friedrich: "Der Fall Wagner". Irïinchen (Goldmann) 1964.

Nietzsche, Friedrich: "Hotzen-Dämmerung". Winchen (Goldmann) 1964.

Nietzsche, Friedrich: "Wietzsche contra Wagner", Minchen (Goldmann) 1964.

Nietzsche, Jigiedrich: "Der Antichrist". Winchen (Goldmann) 1964.

Nietzsche, Fiedrich: "ner Wille zur Macht". Mit einem Nachwort von Alfred Bäumlex: Stuttgajt: (Kröner) 1964.

Nietzsche, Higiedrich: Wece Homo". Minchen (Goldmann) 1964.

Nietzsche, Hrịedrich: "Die Unschuld des Werdens. Der Nachlass". Herausgegebeñ und mit einem Nachmort von Alfred Bäumler. Stuttgart (Kroner) 1956.

Risse, Heinz: "Paul Cézanne und Gottfried Benn". Munchen (Íangen/Riiller) 1957.

Schimann, Kurt: "Gortfried Benn: Eine Studie". Imsdetten (techte) 1957.

UImer, Karl: "Nietzsche. Einheit und Sinn seines Werkes". Bern (Franke) 1962.

Wolff, Hans M: "Friedrich Nietzsche. Der Weg zum Nichts". Bern (Franke) 1956. 